\title{
Social allostasis: anticipatory regulation of the internal milieu
}

\author{
Jay Schulkin ${ }^{1,2 *}$ \\ 1 Department of Neuroscience, Georgetown University, Washington, DC, USA \\ 2 National Institute of Mental Health, Bethesda, MD, USA
}

Edited by:

Simon Baron-Cohen,

University of Cambridge, UK

Reviewed by:

Rebecca Burch

State University of New York at

Oswego, USA

Justin R. Garcia, Binghamton

University, USA

*Correspondence:

Jay Schulkin, 409 12th St SW,

Washington, DC 20024, USA.

e-mail: jschulkin@acog.org

\begin{abstract}
Social regulation of the internal milieu is a fundamental behavioral adaptation. Cephalic capability is reflected by anticipatory behaviors to serve systemic physiological regulation. Homeostatic regulation, a dominant perspective, reflects reactive responses; allostatic regulation, the physiology of change, emphasizes longer-term anticipatory, and feedforward systems. Steroids, such as cortisol, and peptides such as corticotrophin releasing hormone are but one example of such anticipatory regulatory systems. The concept of "allostasis" is in part to take account of anticipatory control amidst diverse forms of adaptation underlying this regulatory adaptation that supports social contact and the internal milieu.
\end{abstract}

Keywords: social, allostasis, regulation, and the internal milieu

\section{INTRODUCTION}

Human evolution placed social knowledge and social context at a premium. Prosocial behavior underlies the moral sensibility that pervades human experience resulting in significant human contact (Darwin, 1958, 1998).

Social contact is a major adaptation in the regulation of the internal milieu, a way in which the information molecules that permeate cephalic and end organ bodily systems interact and result in behavioral and physiological activity; many of the same information molecules that are produced in the periphery (e.g., stomach, heart) are produced in the brain. There is quite a diverse set of them [e.g., corticotrophin releasing hormone (CRH), oxytocin, vasopressin, angiotensin, prolactin, melatonin, serotonin, insulin, leptin; Herbert, 1993; Fitzsimons, 1999; Power and Schulkin, 2009].

One feature of our species' brain is the presence of multiple mechanisms that provide the potential for cephalic anticipatory adaptation - that is, the brain constantly attempts to anticipate future events. This is paramount in larger cast social orders, and adaptation is achieved, in part, by cephalic regulation of behavioral and physiological systems in the expression of longer-term adaptation (Sterling and Eyer, 1988; McEwen and Stellar, 1993; Schulkin, 2003).

The concept of allostasis (see below) in its original meaning was tied to diverse and expanding social demands; social contexts that expanded and stretched mammals and perhaps particularly in primates beyond reflexive immediacy and deviations in set point physiology. In fact, a close look at regulation almost always reveals something more than simple reflexes and deviations from set point parameters. In the social domain, and with a consideration of evolution, enhanced use of behavior, and social skills emerged to regulate viability (Sterling, 2004).

Allostatic regulation emphasizes feedforward regulatory systems, anticipatory, and essential for adaptive social behaviors (Sterling and Eyer, 1988; Schulkin et al., 1998). Diverse information molecules (e.g., oxytocin, prolactin, vasopressin, corticotrophin hormone) code for diverse socially adaptive behaviors; they are regulated, in part, by steroids in diverse regions of the brain. For instance, chemical messengers in the brain, such as CRH or vasopressin, oxytocin, or prolactin, are regulated by steroid hormones in different regions of the brain that underlie diverse behaviors, including approach and avoidance behaviors and physiological systems (Herbert, 1993; Carter et al., 1999; Pfaff, 1999; Schulkin, 1999; Keverne, 2004a,b).

In this review, I begin first with a brief discussion of the concept of allostasis, then information molecules (e.g., cortisol, CRH) then a discussion of behavioral social regulation to a conception of diverse feedforward systems and then to devolution of function (allostatic overload). Our well-being is linked to social context, and social attachment reflects larger forms of regulatory competence.

\section{ALLOSTASIS}

The concept of "Allostasis" was introduced to take account of the physiology of change and adaptation to diverse circumstances and to the behavioral and physiological anticipation of future events (Sterling and Eyer, 1988; McEwen and Stellar, 1993; Schulkin, 2003). The concept has been centered in cephalic anticipatory regulation of the internal milieu in the context of a social framework: changing circumstances, adapting to change, and features that are not fully grasped in traditional accounts of homeostatic regulation (maintain glucose levels at one level) of the internal milieu (Schulkin, 2003). Allostatic regulation emphasizes a central state of the brain (Sterling and Eyer, 1988; Schulkin, 2003; Koob and LeMoal, 2005; Ganzel et al., 2010).

"Allo" means change, whereas "stasis" means stable/same. But social milieu changes; we invoke both cognitive and physiological resources to promote continuity, stability, and predicted outcomes. The "allo" part of "stasis" is "about adapting to change" to achieve the goal of stability in the face of uncertain circumstances, something all of us know about early in life and throughout life. The emphasis is on how we achieve internal viability in adapting 
to changing circumstances within parameters essential for life processes; chronic overactivity of regulatory systems render one vulnerable to pathophysiology.

Traditional conceptions of regulation have typically (though not always) emphasized homeostatic short-term regulation, with further focus on set point stability and short-term contemporaneous adaptation (Cannon, 1929; Chrousos and Gold, 1992; Goldstein, 1995; Dallman, 2003). The expansion of cortical function, in social groups of diverse complexity, entails longer-term regulation.

Anticipatory regulation underlies our evolutionary ascent and is a core feature of allostatic regulation. We are species for which we are not simply reactive in the narrow sense of responding to a need or deficit after it happens, we anticipate the events. Regulation of the internal milieu has mostly been construed as restoring deficits, much less about anticipating them, the cognitive resources that reflect the cephalic innervation and maximal use of bodily resources toward long-term viability. Predictive responses are a primary adaptation in human evolution (Moore-Ede, 1986; Bauman, 2000; Schulkin, 2003; Sterling, 2004; Gluckman et al., 2005; Romero et al., 2009).

Homeostatic regulation is too passive a notion for the resources required to maintain long-term viability and reproductive success. Traditional homeostatic theories were too passive in the consideration of brain involvement in shifting the emphasis toward longerterm considerations. The shift does not entail any mythological aggrandizement of perfect rationality, just longer-term considerations in our adaptive responses.

Allostatic considerations, amongst others shifts the emphasis less in terms of maintaining a particular balance for example ionic balance, and more terms of the range of balances that are possible in an adaptive individual coping with a changing environment (Sterling and Eyer, 1988).

Homeostatic regulation and its conceptual basis were knotted to laboratory considerations (Cannon, 1929, 1963), the depletion/repletion model became the standard way to tease apart the maintenance of the internal milieu (Cannon, 1929, 1963; Richter, 1943; Bernard, 1859). But once behavior was introduced as an essential role in sustaining long term viability and not simple stability, a conceptual shift emerged. Behavioral adaptation and regulation is a fundamental way in which physiology viability is maintained; allostatic regulation emphasizes regulatory flexibility and cephalic expansion.

Allostasis was developed due to a need to conceptualize adaptation to change in a way that took account of all the exigencies of the environment and changing circumstance (e.g., Power, 2004; Wingfield, 2004). The emphasis is on how we achieve internal viability in adapting to changing circumstances within parameters essential for life processes; chronic overactivity of regulatory systems render one vulnerable to pathophysiology.

Allostasis emphasizes regulation that is an adaptation to change; not just in reaction to it, but in anticipation of it (Moore-Ede, 1986; Bauman, 2000). Unpredictable events are a constant feature of the life cycle for most animals (Wingfield et al., 1999; Wingfield, 2004), and the need for stability and consistency are a constant feature of most animals, within both the physiological and social domains; allostasis is a means of achieving stability in the face of unpredict- ability One type of allostatic overload has been thought to be linked to situations when energy demands and exceeds capability; another when there is dysregulation of energy regulation linked to social functions (McEwen and Wingfield, 2003, 2010; Wingfield, 2004).

\section{ANTICIPATORY REGULATION AND COGNITIVE/VISCERAL ADAPTATION}

The concept of heterostasis was introduced by Selye (1956): "Natural homeostatic mechanisms are usually sufficient to maintain a normal state of resistance. When faced with unusually heavy demands, however, ordinary homeostasis is not enough. The 'thermostat of defense' must be raised to a higher level. For this process, I proposed the term heterostasis (from the Greek heteros = other) as the establishment of a new steady state by treatment with agents which stimulate the physiologic adaptive mechanisms through the development of normally dormant defensive tissue reactions. Both homeostasis and heterostasis, the milieu interior participates actively." A number of other scholars have generated similar concepts.

- Moore-Ede (1986), Moore-Ede et al., 1992

- Predictive homeostasis is an anticipatory adaptation and is distinguished from "reactive homeostasis." This distinction arose in the context of considerations of circadian timing systems in the brain and their role in behavioral and physiological regulation in the anticipation of future needs when they appear.

- Mrosovsky (1990)

- Coined the term "rheostasis," like the term "predictive homeostasis," it was generated to account for the variation in physiological systems, depending on season, time of day, and context.

- Bauman (2000)

- Used the term homeorhesis. "The coordination of body tissue metabolism involves two types of regulation, homeostasis and homeorhesis. Homeostatic regulation involves the maintenance of physiological equilibrium; hence this control operates on a minute-by-minute basis to maintain constant conditions within the internal environment. Homeorhesis represents the orchestrated or coordinated changes in metabolism of body tissues to support a physiological state."

Allostatic considerations, like these others, shifts the emphasis less in terms of maintaining a particular balance, for example ionic balance, and more in terms of the range of balances that are possible in an adaptive individual coping with a changing environment (Sterling and Eyer, 1988). Of course the concept of allostasis may not last the test of time in terms of utility (c.f. Dallman, 2003; Schulkin, 2003; Carpenter, 2004; Power, 2004; Day, 2005 ; Romero et al., 2009). Homeostatic regulation is about maintaining the same conditions; allostasis emphasizes change. Change is the core feature of evolution and successful adaptation, and the ability to adapt to change is a core feature of our cephalic ascent. Fixed responses serve end points in environments that remain the same, and indeed a range of variation remains constant in long-term adaptation or viability. 
In fact many investigators have argued that set point outlooks that are strictly homeostatic are not adequate to explain the behavioral role (e.g., Toates, 1986; Berridge, 2004). The hydraulic model of depletion and repletion (e.g., Freud, 1959; Lorenz, 1965, 1981) is a limited perspective on the adaptive and opportunistic regulation of the internal milieu. It is not inaccurate, but there is greater variation in biological adaptation and long-term viability across different kinds of animals in nature than the homeostatic model allows for.

Moreover, the objects that a species requires often shift toward hedonic reward. They are required but they are also perceived as more palatable, thereby facilitating the motivation to acquire them. This is normal adaptation in the regulation of the internal milieu; in omnivores, like the rat, there can be over-consumption of saltladen commodities under conditions of sodium hunger or under conditions of sodium repletion; there is no perfect homeostatic set point. There is just opportunistic ingestion, and certainly in our species, another omnivore, a vulnerability to over-consumption (Schulkin, 2003).

Adaptation, in other words, is the norm, while homeostatic regulation is highly theoretical. Information molecules that traverse both the peripheral and central nervous system underlie the organization of action, the recognition of the familiar and unfamiliar, the approach and avoidance of objects, the evaluation of events; neuropeptides are organized around diverse behavioral functions, rarely one; they are too valuable a resource to be utterly restrictive to one function.

Life cycles for many species are both predictable and unpredictable. Seasonal changes are predictable, as are light/dark cycles. But unpredictable events obviously pervade the seasonal changes. They include climate changes such as severe droughts, food shortages, or disruption of social status (Ricklefs and Wikelski, 2002; Wingfield, 2004).

Disruption of social status, like most events, impacts cortisol levels. But levels of cortisol for instance by itself is not a measure of dominance or not, but of the way in which dominance is achieved (e.g., Saltzman et al., 1998; Cavigelli et al., 2003). One recurrent theme is that social support is predictive of cortisol levels, mitigating diverse events which would elevate it in combating adversity (Abbott et al., 2003). Consider what it is like for a wolf pup under the care of the alpha female who heads the group, then she is killed; the offspring is vulnerable, depending upon social alliances, the age and strength of the offspring, the terrain and social milieu.

Many different cognitive and physiological systems are involved with anticipating future events, including biological events that factor significantly into survival. Homeostasis has been linked to reflexive reactions, not cognitive anticipation of events and cephalic innervation and regulation of peripheral physiological adaptation. And they underlie the immediate sizing up of a social event, through the eye contact and bodily postures, through forms of encoding complex and not so complex social relationships. Think about how fast we are as a species, although sometimes utterly mistaken, in our assessment of possible threat, or possible social comfort.

The emphasis from a social allostatic perspective is on cephalic changes as a result of behavioral adaptation, involving physiology through social relationships, building an environment, use of tools, etc. This is fundamental to the concept of allostasis. In addition, the concept of allostasis and allostatic overload, pushing the system beyond its adaptive capability, is designed to account for vulnerability to disease by taking into account variations in individual experiences and genetic makeup, and to determine how a lifetime of short- and longer-term adaptation impacts wear on the body (Sapolsky, 1992; McEwen and Stellar, 1993; Cacioppo and Bernston, 2007). Biology is designed to promote both short and longer term viability (Power and Schulkin, 2009).

\section{SOCIAL, COMPLEXITY, CORTEX, AND THE BEHAVIORAL REGULATION OF THE INTERNAL MILIEU}

Human prenatal and postnatal development is long and varied in our species, tied as it is to the necessity of the acquisition of a huge body of knowledge during the early period. There is profound change in brain morphology and development during the protracted neonatal period in varying degrees in most mammals (Goy and McEwen, 1980; Arnold and Breedloev, 1985; McCarthy, 2008). And hormones such as oxytocin vital for parturition, for the birth process and for lactation and social attachment figure throughout the gestational and developmental periods.

Regulation of the internal milieu is linked to the social environment, a connection that succeeds or fails in the balance between cooperation and competition for resources. What appears to have evolved in Homo sapiens is a "cognitive penchant" for long-term considerations derived from social cooperation and social knowledge (e.g., Darwin, 1874, 1958; Foley, 1996).

Moreover, what is distinctive about us, although our species is not alone, is the degree to which we share and participate toward common ends; shared intentions linked to the considerations of others is one of our most important cognitive adaptations (Kagan, 1984; Tomasello et al., 1993).

In our species, we look at others; it is not surprising that vision, shared visual space, and recognition that we are both looking at the same objects would come to be important cognitive resources (Tomasello, 1999). But it is not simply a cognitive detached event; it is affectively rich, reassuring, and rewarding. The motivation to form meaningful contacts is essential for development and for life.

Depicted below are some common themes in our cognitive development, particularly that of social development, in Table $\mathbf{1 .}$

A diverse set of neuroendocrine systems knotted to cognitive capacity is encoded to ensure meaningful contact in development, and throughout life; devolution of function (e.g., autism) is the diminishment of this important capacity. Our evolution favored social contact, group formation in which diverse cognitive skills facilitate the formation of social bonds.

From the point of view of the brain for all primates, two kinds of regulation are taking place: the regulation of the internal milieu, and adaptation and regulation of the social milieu. Both require a brain with diverse physiological and behavioral regulatory systems. In both cases, anticipatory mechanisms underlie adaptation both within the individual and within the social milieu. The greater the degree of social contact and social organization experienced by a human, the greater the trend for cortical expansion (Dunbar, 1998; Barton, 2006; Dunbar and Shultz, 2007; see Figure 1). 
Most primates are highly social except for the solitary orangutan, with the exception, of course, of a long relationship between the mother and her offspring, present in all primates, including the orangutan (Robson and Wood, 2008; see Figure 2).

Core features in the origins of the genus Homo consist of some of the following (Stringer and Andrews, 1988; Robson and Wood, 2008): longer gestational period, long life spans, forward locomotion with heel and hind limb dominance, dominance of stereoscopic vision and forward movement of the eyes, and expanding use of the hands.

Physiological cognitive systems are oriented to the social milieu. Their evolution and expression underlie the diverse forms of complicated social assessments; group size, for instance, is correlated with cortical expansion (Dunbar and Shultz, 2007). Consider the complex social relationships of primates, the hierarchy, and the distribution of food resources, shelter protection, dominance, and comfort through co-alliances. Such systems are quite varied and all involve cephalic innervations and expression.

\section{Table 1 |Themes in our cognitive development.}

\section{INFANCY: UNDERSTANDING OTHERS AS INTENTIONAL}

1. Following attention and behavior of others: social referencing, attention following, imitation of acts on objects

2. Directing attention and behavior of others: imperative gestures, declarative gestures

3. Symbolic play with objects: playing with "intentionality" of object

\section{EARLY CHILDHOOD: LANGUAGE}

1. Linguistic symbols and predication: inter-subjective representations

2. Event categories: events and participants in one schema

3. Narratives: series of interrelated events with some constant participants CHILDHOOD: MULTIPLE PERSPECTIVES AND REPRESENTATIONAL RE-DESCRIPTIONS

1. Theory of mind: seeing situation both as it is and as other believe it to be

2. Concrete operations: seeing events or object in two ways simultaneously

3. Representational re-description: seeing own behavior/cognition from "outside" perspective

Adapted from Tomasello et al. (1993).

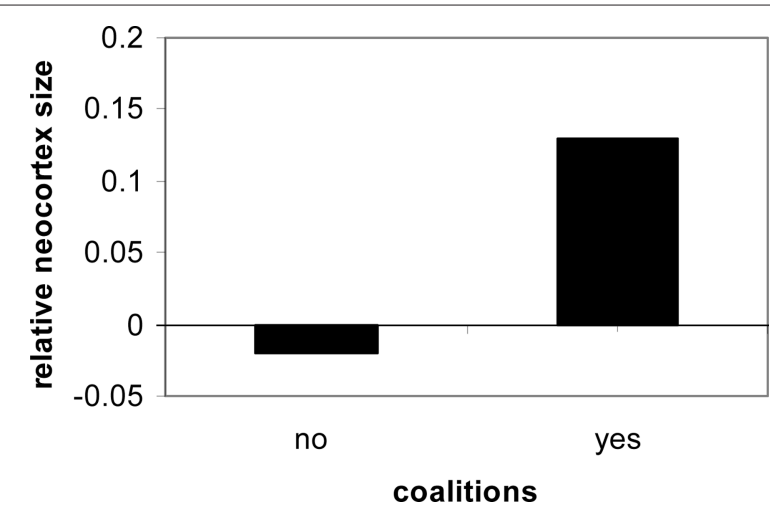

FIGURE 1 | Social contact in primates is consistently linked to neocortical expression and size (Dunbar and Shultz, 2007).
The Table below depicts the morphological core feature that is unique to Hominoids (Table 2).

Finally, depicted below is an endocast of the frontal region of a putative Homo around two million years ago and a representation of (a) chimpanzee, (b) orangutan, (c) gorilla, and (d) human frontal plane (Falk, 1983). Frontal cortical expansion is a primary feature of each illustration (Figure 3; Table 3).

\section{CORTISOL}

Cortisol is important in the conversion of short to longer-term memory (McGaugh, 2000). Experiments demonstrate that cortisol, perhaps by facilitating norepinephrine, influences memory formation (Roozendaal et al., 1996, 2001); it is a fundamental neurotransmitter in the brain which contributes to the consolidation and the induction of short- to long-term memory as the memory in the brain - broadcasting the memory to diverse regions of the brain (McGaugh, 2000; Roozendaal, 2000; Kukolja et al., 2008). In other words cortisol impacts regions of the amygdala (McGaugh, 2000; Roozendaal, 2000; Donley et al., 2005, lateral region) which is vital for memory formation.

Put slightly differently, the induction of the neurotransmitters related to adrenalin in the brain and the regulation of their expression in diverse regions of the brain (e.g., amygdala, hippocampus,

\section{Table 2 | Defining characters of homo.}

\section{CHARACTERS UNIQUE TO ALL SPECIES OF HOMO, AS DISTINCT} FROM OTHER HOMINIDS

Increased cranial vault thickness

Reduced postorbital constriction

Increased contribution of occipital bone to cranial sagittal arc length

Increased cranial vault height

More anterior foramen magnum

Reduced lower facial prognathism

Narrower tooth crowns, especially mandibular premolars

Reduction in length of the molar tooth row

\section{CHARACTERS SHARED BY H. HABILIS AND H. RUDOLFENSIS, AND UNIQUE TOTHESE SPECIES}

Elongated anterior basicranium

Higher cranial vault

Mesiodistally elongated first and second molars

Narrow mandibular fossa

Adapted from Wood (1992).

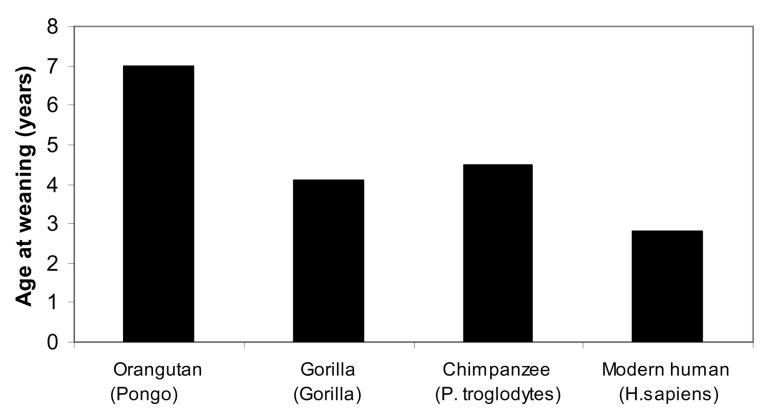

FIGURE 2 | Primates, age of weaning (Robson and Wood, 2008). 

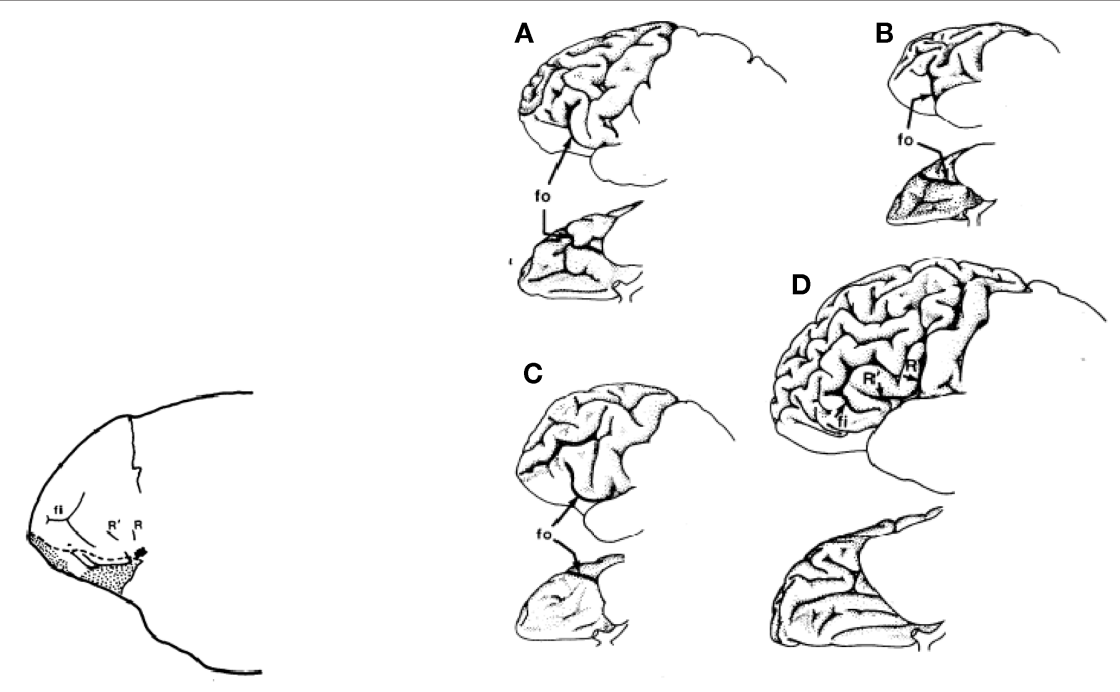

FIGURE 3 | Frontal cortical expansion in putative Homo Falk (1983). Left frontal lobes (lateral view above rotated to basal view below) of (A) chipanzee, (B) oangutan, (C) gorilla, and (D) human.

Table 3 | Encephalization quotient (EQ) of various extant and fossil species.

\begin{tabular}{lll}
\hline Species & Date range & EQ \\
\hline Australopithecus afarensis & $3.9-3.0 \mathrm{Mya}$ & 2.5 \\
Paranthropus boisei & $2.3-1.4 \mathrm{Mya}$ & 2.7 \\
Paranthropus robustus & $1.9-1.4 \mathrm{Mya}$ & 3.0 \\
Homo habilis & $1.9-1.6 \mathrm{Mya}$ & 3.6 \\
Homo ergaster & $1.9-1.7 \mathrm{Mya}$ & 3.3 \\
Homo erectus & $1.8 \mathrm{Mya}-200 \mathrm{Kya}$ & 3.61 \\
Homo heidelbergensis & $700-250$ Kya & 5.26 \\
Homo neanderthalensis & $250-30$ Kya & 5.5 \\
Homo sapiens & 100 Kya - present & 5.8 \\
\hline
\end{tabular}

Adapted from Power and Schulkin (2009).

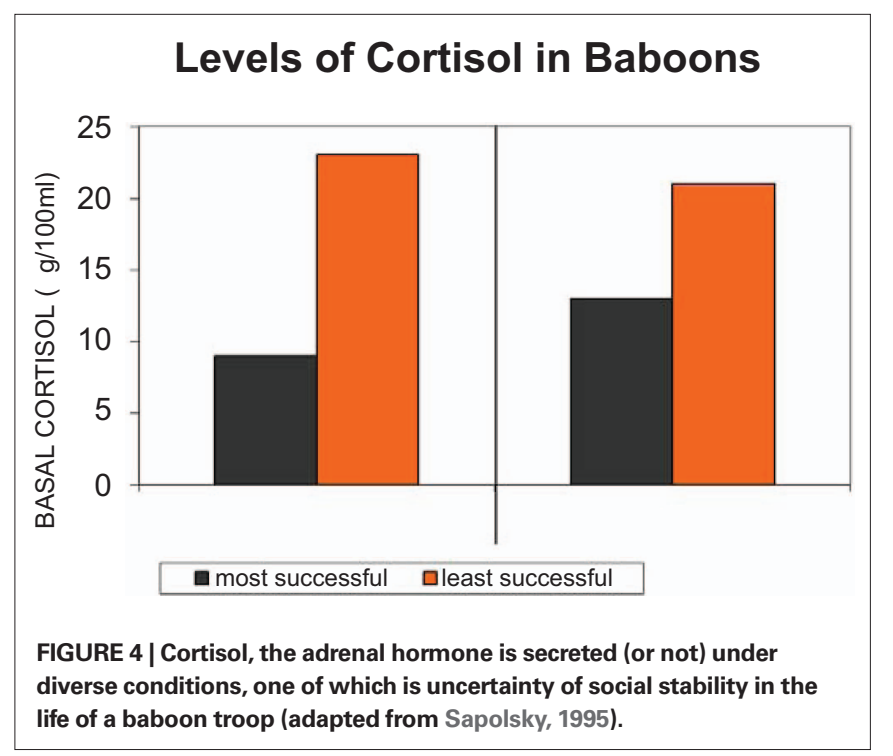

regions of the neocortex) than broadcasts the memory event to diverse regions of the brain that underlie memory (e.g., McGaugh, 2000, 2003; Roozendaal et al., 2002). Importantly, cortisol has diverse effects on end organ systems, in regulating glycogenesis and whole body regulation and one such form of regulation is central neurotransmitter regulation and the facilitation of memory formation.

But cortisol function is broad in regulatory behavioral and physiological regulation; moreover, glucocorticoids vary their effects in seasonal variation, in droughts, and in predictability for the allocation of food resources and other metabolic requirements (Buttemer et al., 1991; Wingfield and Romero, 2001; Goymann and Wingfield, 2004; Landys et al., 2006). Glucocorticoids are not a onedimensional entity. They are multidimensional in action and effect, and thus fundamental to biological and social adaptation. Their effects are both short-term adaptations and long-term detriment, which are depicted in Table 4.

Thus glucocorticoids, for instance, promote foraging behavior in many different animals under various conditions, and facilitate life processes essential for successful reproduction, energy metabolism, and attention to external events (Sapolsky, 1992; Dallman et al., 1994; Schulkin, 2003). The important point in understanding regulatory physiology promoting viability over time is the adaptive nature of actions of different hormones depending upon the circumstances both internal and relative to niche and circumstance (Wingfield et al., 1999; Adkins-Regan, 2005).

Cortisol, long referred to as the hormone of "stress," is mischaracterized when understood in this way. It is the hormone of energy metabolism and adaptation through which different end organ systems are mobilized or restrained for action (Sapolsky, 1992; Dallman et al., 1994; McEwen and Wingfield, 2003; Schulkin, 2003). An important consideration in the successful aging process, a cumulative biological marker is the regulation of cortisol, namely the ability to secrete more of it when necessary and terminate the 
Table 4 | Effects of glucocorticoids.

Short-term adaptation

Regulation of immune system

Increase glycogenesis

Increase foraging behavior

Increase activation of the brain

Long-term disruption

Disruption of immune response

Protein loss

Growth and reproductive disruption

Bone loss

Brain deterioration

Adapted from Wingfield and Romero (2001).

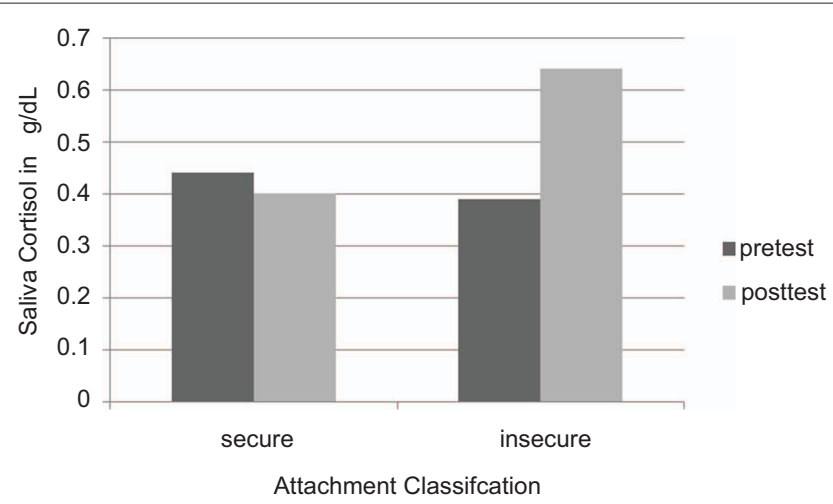

FIGURE 5 | Salivary cortisol concentrations in 18-month-old infants who feel securely attached to their mothers, versus insecure infants. (Redrawn from Nachmias et al., 1996, with permission).

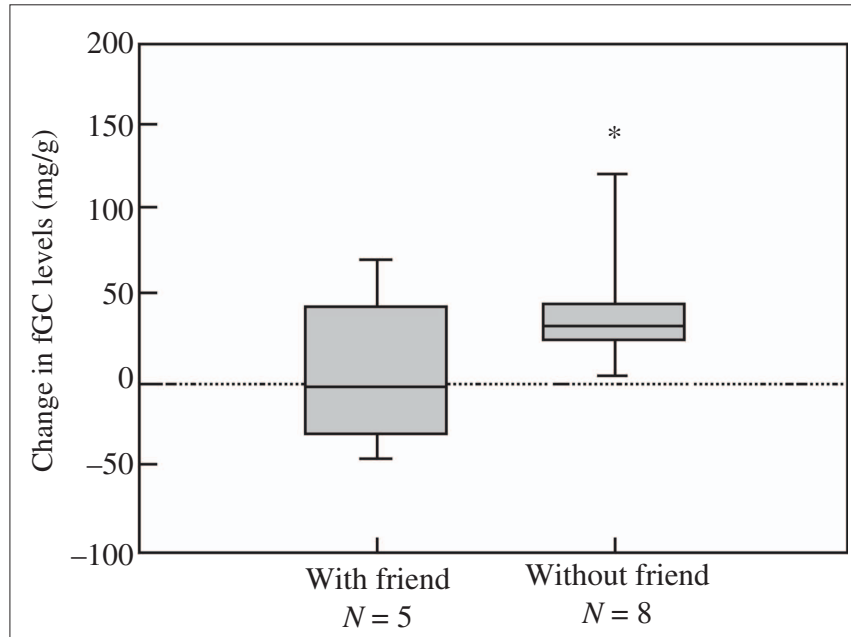

FIGURE 6 | Reliable alliances a fundamental feature for longevity; cortisol is higher without strong alliances, friendship, in this troop of female baboons Engh et al. (2006b). elevated levels when not necessary (Sapolsky et al., 2000; Seeman et al., 2001). These are ameliorated or not by social context, genetics, and Fortuna.

\section{SOCIAL CONTACT AND CORTISOL}

The secretion of cortisol is an adaptive response serving physiology and behavior. The continued secretion of cortisol without relief has consequences though; bone demineralization, compromised immune system, and shifts in metabolism are the result of secretion of cortisol (Sapolsky, 1992, 1995). One important adaptation is regulation of the internal milieu - that is, the secretion of cortisolthrough manipulations in the social context.

And there is an important social adaptation designed to reduce elevated levels of cortisol back to normal. Social attachment, the formation of core safe, or relatively safe attachments, provide feedback on the expression of steroid levels such as cortisol and the regulation of the internal milieu.

The emphasis however is on social competence (which would include cooperative behavior in tool use), but also on an evolved set of anticipatory mechanisms that facilitated the regulation of the internal milieu amidst an expanding social milieu, since we are social animals. And these behavioral adaptations are impacting the brain directly; evolution selected for behavioral adaptations to feed back directly onto cephalic function.

For example, cortisol tends to be elevated in troops of macaque monkeys under conditions of uncertainty, including uncertainty of social control (Sapolsky, 1992). Perception of where an individual baboon is in the hierarchy of its social group influences the internal milieu, particularly cortisol levels. In addition, social perception, facilitating social approach or avoidance, results in the behavioral regulation of cortisol (Sapolsky, 1990; Cheney and Seyfarth, 2007).

But it is not axiomatic that cortisol is elevated in the downtrodden, insecure members of primate groups (c.f. Sapolsky, 1990, 1992, 1995; Saltzman et al., 1994, 1998; Creel, 2001). Behavioral adaptation can result in elevated levels of cortisol in many contexts (Abbott et al., 2003). It is not the case with cortisol that elevated levels equals adversity. The important point about cortisol is not whether it is elevated in dominance or the socially less fortunate group member, but whether there are behavioral strategies for regulating it; turning it off, decreasing and increasing the level when necessary and its costs when not, social status. Social comfort is one such strategy (Sapolsky, 1995; Wingfield, 2004). In an interesting confluence of two disciplines, the cognitive ethological literature and the endocrine regulatory literature, the social milieu is long known in both to help regulate steroid levels (e.g., Eberhart et al., 1980; Sapolsky, 1990, 1995; Figure 4).

In humans, like several other mammalian species (e.g., macaques, baboons, Sapolsky, 1990; Erickson et al., 2005), social contact under conditions of uncertainty can reduce cortisol secretion. For instance, grooming behavior is a fundamental form of social organization. Grooming behavior is involved in sustaining alliances amongst group members, in the formation of new alliances, appeasement, comfort, and attachment - "friendships" during conditions of adversity impact for instance cortisol levels (Cheney and Seyfarth, 1990, 2007). In other words complex 


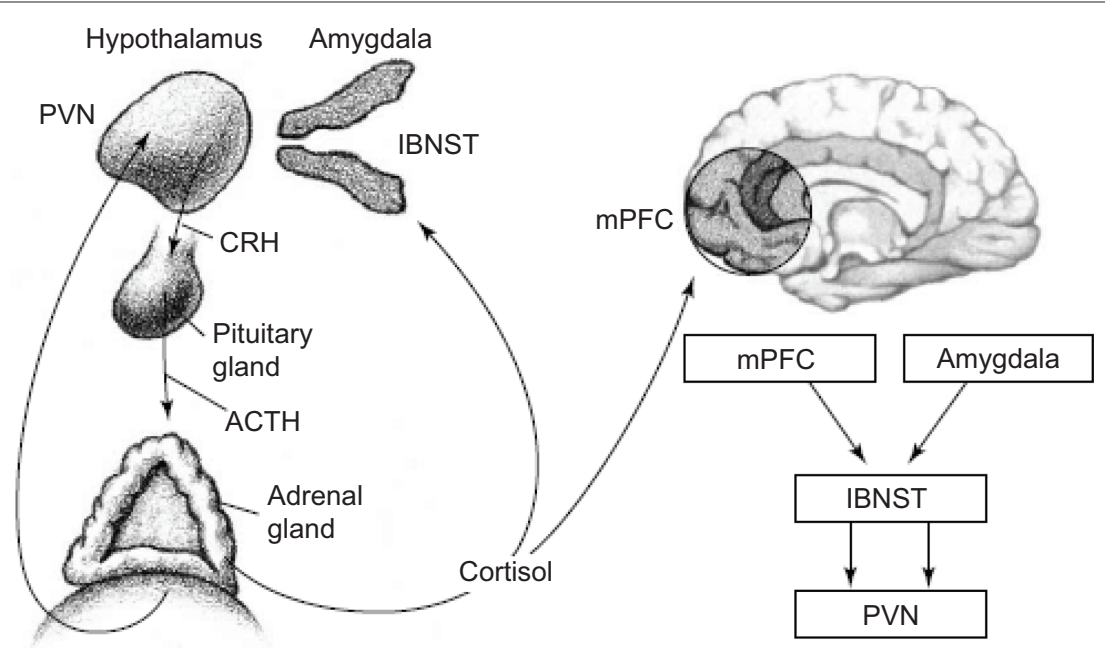

FIGURE 7 |The hypothalamic-pituitary-adrenal (HPA) axis and its interactions with key forebrain regions that underlie adversity. Release of $\mathrm{CRH}$ from the paraventricular nucleus (PVN) of the hypothalamus stimulates release of adrenocorticotropic hormone (ACTH) from the pituitary gland. ACTH in turn stimulates release of cortisol from the adrenal glands, which provides negative feedback to the PVN. During fear, cortisol also acts on the medial prefrontal cortex (mPFC) and amygdala; these regions provide feedback to the PVN, via the lateral bed nucleus of the stria terminalis (IBNST; Schulkin et al., 2005). alliances are kept on track and are modulated by grooming behaviors. This pattern of behavior, because it is linked to tracking of complex hierarchical relationships, represents a highly cognitive adaptation fundamental for group coherence (Cheney and Seyfarth, 1990, 2007).

So social contact is one way of managing the secretion of cortisol. More social contact, more grooming, less cortisol circulating; forming coalitions is essential for the regulation of the internal milieu, of which cortisol, the molecule of energy metabolism, is one molecule amongst others being regulated by social contact (Sapolsky, 1992; Schulkin, 2003). In a similar way, young children who form social contact and seek out human warmth and security tend to have lower levels of cortisol under diverse conditions (Gunnar et al., 1989; Gunnar, 1998; Gunnar and Davis, 2005; Figure 5).

An important adaptation are the formation of social contact and keeping track of alliances, amongst other social events (Cheney and Seyfarth, 1990, 2007).The social context then feeds back upon the secretion of the steroid, for instance, cortisol. And steroid hormones such as cortisol have diverse effects on the brain; they regulate the production of genes that produce neuropeptides (e.g., CRH), which are a common final pathway in promoting the behaviors that underlie approach and avoid, sustain and persevere in the myriad of social and complex behaviors (Palombti et al., 1997). With coalitions or friendships, cortisol is a bit lower in many studies of primates and other animals in the wild (Engh et al., 2006a; Figure 6).

Disruption of social status like most events impacts cortisol levels. Levels of cortisol for instance by itself is not a measure of dominance or not, but the way in which dominance is achieved (e.g., Saltzman et al., 1998; Cavigelli et al., 2003). One recurrent theme is that social support is predictive of cortisol levels, mitigating diverse events which would elevate it in combating adversity (Abbott et al., 2003).
There is an important social adaptation designed to reduce elevated levels of cortisol back to normal is social attachment; the formation of core safe, or relatively safe attachments, feedback on the expression of steroid levels such as cortisol and the regulation of the internal milieu.

The emphasis however is on social competence (which would include the cooperative behavior in tool use) but also an evolved set of anticipatory mechanisms that facilitated the regulation of the internal milieu amidst an expanding social milieu, since we are social animals. These behavioral adaptations are impacting the brain directly; evolution selected for behavioral adaptations to feedback directly onto cephalic function (Herbert and Schulkin, 2002).

\section{FROM NEGATIVE RESTRAINT TO ALLOSTATIC REGULATION; BEYOND THE HYPOTHALAMIC-PITUITARY-ADRENAL AXIS}

Chemical messengers in the brain, such as CRH or vasopressin, oxytocin or prolactin, are regulated by steroid hormones in different regions of the brain that underlie diverse behaviors, including approach and avoidance behaviors and physiological systems (Herbert, 1993; Carter et al., 1999; Pfaff, 1999; Schulkin, 1999; Keverne, 2004a,b). One recurrent and constant theme in social allostasis is the relationship between steroids, such as estrogen, testosterone, cortisol, and central neuropeptides or neurotransmitters in the regulation of behavior.

Feedforward regulatory systems are endemic to neural function and behavioral regulation of the internal and social milieu; it is an important component of allostatic mechanisms as is the social regulation mediated by neuropeptide expression.

While an exaggerated emphasis has been on negative restraint as a primary model for steroid peptide interactions (though see Kalya, 1993; Fink, 1997) on the model of the hypothalamicpituitary-adrenal axis, the behavioral model is less in conformity 
with this view (see Fluharty and Epstein, 1983; Herbert, 1993; Schulkin et al., 1998; Pfaff, 1999). The inhibition of CRH by cortisol is profound, though it is not always expressed under conditions of adversity (Dallman et al., 1987; Swanson and Simmons, 1989; Imaki et al., 1991; Chrousos and Gold, 1992; Watts and Sanchez-Watts, 1995; Chrousos, 1996). Indeed many forms of adversity in which cortisol is elevated does not result in the inhibition of CRH in the parvocellular region (e.g., withdrawal from psychotropic drugs, restraint stress, e.g., Koob and LeMoal, 2005).

Glucocorticoids increase CRH gene expression in the central nucleus of the amygdala, lateral bed nucleus of the stria terminalis and infralimbic medial prefrontal cortex (Makino et al., 1994a,b; Watts and Sanchez-Watts, 1995; Cook, 2002; Dallman et al., 2003; Thompson et al., 2004; Merali et al., 2008), while they decrease $\mathrm{CRH}$ gene expression in the classical fashion in the parvocellular region of the periventricular nucleus (Swanson and Simmons, 1989; Makino et al., 1994a,b; Watts and Sanchez-Watts, 1995; Dallman et al., 2003). In fact, even within the paraventricular nucleus (PVN), $\mathrm{CRH}$ neurons that project to the brainstem are not restrained by glucocorticoids and CRH elsewhere in the brain are not restrained in production by glucocorticoids (Swanson and Simmons, 1989; Valentino et al., 1993; Watts and Sanchez-Watts, 1995; Shepard et al., 2000; Cook, 2002; Thompson et al., 2004; Figure 7).

Corticotrophin releasing hormone, a signal about danger amongst other things in the brain, mobilizes action; if at a water spout or a feeding place the animal would flee. To sustain the fear, the adrenal gland is activated in the mobilization of coherent action, and in this regard the CRH release is sustained (Cook, 2002). In other words, the initial release of CRH is independent of the adrenal gland hormone cortisol, the second release is cortisol dependent, since blocking its release reduces $\mathrm{CRH}$ expression in the amygdala (see Figure 8).

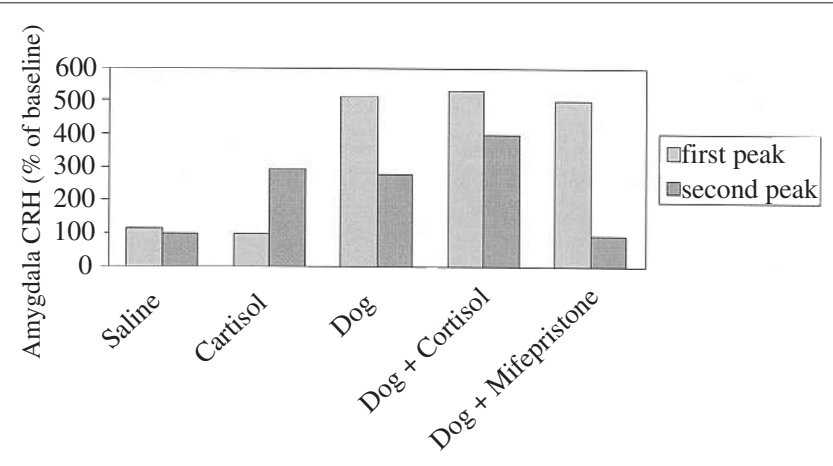

FIGURE 8 | Corticotrophin releasing hormone responses in amygdala of sheep exposed to a dog and/or drugs, expressed as percentage of baseline amygdala $\mathbf{C R H}$. A 6-min exposure to a dog produced a biphasic $\mathrm{CRH}$ response: an initial rapid increase in $\mathrm{CRH}$ levels in the presence of the dog, followed 20 min later by a second $\mathrm{CRH}$ peak that was smaller in magnitude and longer in duration than the first, occurring in response to rising levels of cortisol. Saline injection had no effect on $\mathrm{CRH}$ levels. Venous administration of cortisol (3 mg kgK1) produced a single $\mathrm{CRH}$ peak, similar to the second $\mathrm{CRH}$ peak produced by dog exposure; the initial rapid increase in $\mathrm{CRH}$ levels seen with dog exposure was not observed. Combined exposure to a dog plus cortisol enhanced the second $\mathrm{CRH}$ peak; exposure to a dog plus a glucocorticoid receptor antagonist eliminated the second $\mathrm{CRH}$ peak. (adapted from Cook, 2002).
In fact the induction of CRH by cortisol in the amygdala is an important adaptation; there are a number of experiments that have shown that corticosterone can facilitate the induction of $\mathrm{CRH}$ gene expression in several regions of the brain; again they include the central nucleus of the amygdala and the bed nucleus of the stria terminalis (Swanson and Simmons, 1989; Makino et al., 1994a,b; Watts and Sanchez-Watts, 1995; Shepard et al., 2000; Thompson et al., 2004; Kolber et al., 2008). Diverse kinds of events can elicit elevated $\mathrm{CRH}$ and diverse neuropeptides or neurotransmitters (bombesin, serotonin, dopamine Merali et al., 1998, 2004, 2008) in several regions of the brain, not just fear related events (e.g., anticipation of food).

The neuropeptides and neurotransmitters are regulated directly by many behavioral adaptations (e.g., Pfaff, 1980, 1999; McEwen, 1995, 2007; Carter et al., 1999; Fitzsimons, 1999; Strand, 1999; Herbert and Schulkin, 2002; Insel and Fernald, 2004; Keverne and Curley, 2004; Goodson, 2005; Choleris et al., 2008). The sight of a
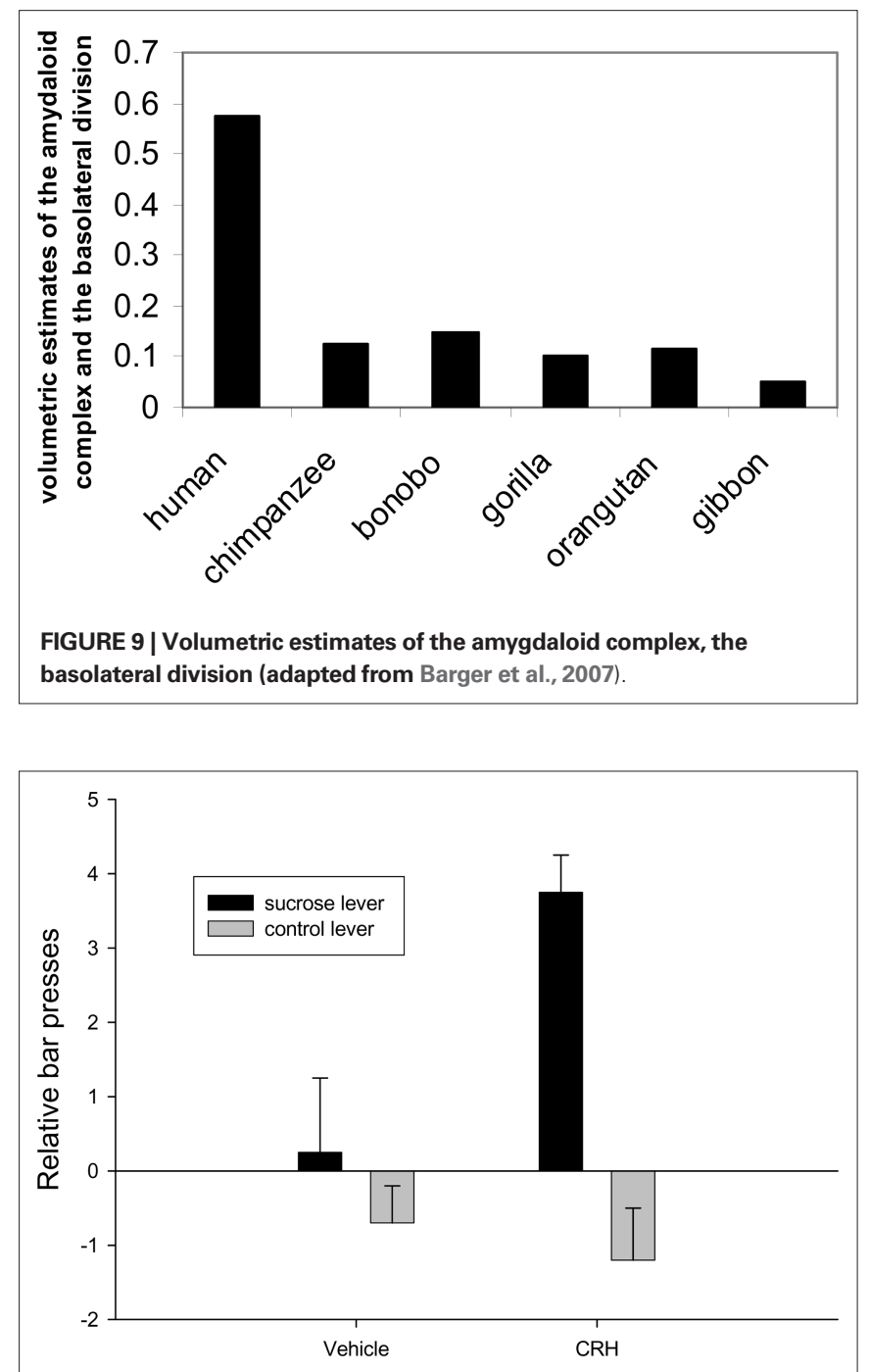

FIGURE 10 | Injections of corticotrophin releasing hormone into the nucleus accumbens results in anticipatory bar pressing for sucrose adapted from Peciña et al., 2006. 


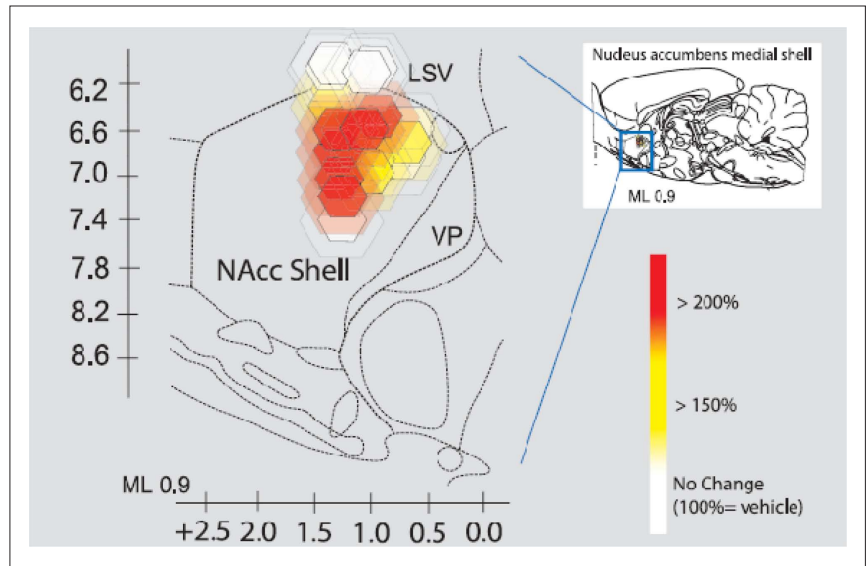

FIGURE 11 | Intracranial infusion of CRH into shell of nucleus accumbens Peciña et al. (2006). Fos plume maps of CRF (500 ng) amplification of cue-triggered increases in lever pressing. Fos plume maps of functional localization: CRF effects on cue-triggered incentive salience. The sagittal map shows each Fos plume as colored symbol in medial shell of nucleus accumbens. Color depicts magnification effect of CRF (500 ng) microinjection at that site on peaks of level pressing triggered by a 30-s auditory CS + previously associated with sucrose reward (within-subject percentage elevation of CRF versus vehicle in the same rat; $100 \%=$ vehicle). Size of central symbol depicts radius of intense Fos elevation; size of surrounding halos depict outer radius of moderate Fos elevation. For the sagittal map, bilateral accumbens sites from the left and right sides of each rat brain are collapsed together into one combined sagittal map of accumbens for simplicity.

predator as noted (a dog, for instance) elicits an immediate release of diverse central information molecules (bombesin, $\mathrm{CRH}$ ); $\mathrm{CRH}$ measured by microdialysis in sheep is but one example (Cook, 2002; see Merali et al., 1998, 2004, 2008). CRH is released under diverse conditions, particular under novelty (Habib et al., 2000; Cook, 2002). The ability for the sheep to remove themselves from the vicinity of the dog, results in a rapid diminution of $\mathrm{CRH}$; behavior serving to regulate central CRH expression (Cook, 2002). The instrumental behaviors are tied avoiding an aversive noxious event, has immediate impacts on $\mathrm{CRH}$ expression or attending to noxious and fear related events, or something unfamiliar or uncertain (Kalin et al., 1989, 2000; Coplan et al., 1996; Merali et al., 1998). One important insight into one behavioral function of $\mathrm{CRH}$ is that it is released when an object is unfamiliar or uncertain, as well as if it is dangerous (e.g., Kalin et al., 1998; Habib et al., 2000).

Diverse social internal systems activate gene expression underlying CRH and many other information molecules in the brain (Kalin et al., 1989, 1998; Herbert and Schulkin, 2002; Ruscio et al., 2007; Yao et al., 2008). And CRH is linked to diverse behaviors: food intake, learning, arousal, and sexual behavior (Kalin, 1985; Kalin et al., 1989, 1998; Merali et al., 1998, 2004, 2008). One key area in which there are both GR and $\mathrm{CRH}$ receptor sites is the lateral region of the amygdala (Makino et al., 1995), an area known to be influenced by both CORT and CRH (Roozendaal, 2000; Donley et al., 2005).

In addition, regions of the amygdala essential for social attachment and avoidance also demonstrate significant changes in us: for instance, enlargement of the lateral amygdala which is closely tied to neocortical function (e.g., Swanson, 2000). The largest nuclear region is the basal lateral region. In one comparative study of apes and humans (e.g., human, chimpanzee, bonobo, gorilla, orangutan, gibbon) investigators found that the size of the lateral division of the amygdala expands quite a bit in Homo sapiens compared to the expansion in other primates (Barton et al., 2003; Barger et al., 2007; Figure 9).

\section{ANTICIPATORY BEHAVIORS, ALLOSTATIC PATHOLOGY, AND CHRONIC AROUSAL: EXAGGERATED SOCIAL SALIENCE}

The widening range of consumable objects turns the volume up in terms of arousal the physiology. The consumption of and withdrawal from known addictive substances (heroin, cocaine, alcohol, barbiturates, amphetamine, marijuana etc.) results in elevated levels of $\mathrm{CRH}$ in at least two regions of the brain; the central nucleus of the amygdala, and the paraventricular nucleus of the hypothalamus (Koob and LeMoal, 2005).

And perhaps glucocorticoids, at least with regard to amygdala function, may enhance $\mathrm{CRH}$ expression and thereby increase the vulnerability to increased salience and attention to those objects associated with these drugs of abuse (Schulkin, 2003). In fact every object of reward (food, drugs etc.) result in enhanced CRH expression in diverse regions of the brain, including the amygdala and frontal cortex and the paraventricular nucleus of the hypothalamus (Merali et al., 2004; Koob and LeMoal, 2005).

In fact, one way to understand these events is that one function of glucocorticoids is to magnify the effects of CRH with increased attention to objects, their potential value etc. (Dallman et al., 2003; Peciña et al., 2006).

The neuropeptide is knotted to attentional responses to both external and internal events (Dallman et al., 2003; Peciña et al., 2006). Peptides such as CRH can increase incentive salience (Dallman et al., 2003; Merali et al., 2004; Peciña et al., 2006). Rats will bar press in anticipation of an expected sucrose reward following $\mathrm{CRH}$ infusion or amphetamine infusions into the nucleus accumbens (Robinson and Berridge, 1993; Peciña et al., 2006; Figure 10).

The next figure depicts the neural site to the intracranial infusion of CRH into what is called the "shell" of the nucleus accumbens (Peciña et al., 2006; Figure 11).

Regulation and anticipatory adaptation have turned into vulnerability and exaggerated consumption. Perhaps glucocorticoids, at least with regard to amygdala function, may enhance $\mathrm{CRH}$ expression and thereby increase the vulnerability to increase attention to those objects associated with drugs of abuse (Schulkin, 2003).

More generally, many of these areas are activated with an expectation of diverse rewards (e.g., sucrose reward. For instance, expectancy for a sucrose reward results in activation of regions of the frontal cortex (Merali et al., 1998, 2004; Dallman et al., 2003; Peciña et al., 2006); in fact both positive and negative events (food ingestion and drug withdrawal, for instance) activate CRH expression in diverse regions of the brain, including the amygdala and frontal cortex and PVN (Merali et al., 2004; Koob and LeMoal, 2005). Interestingly, using microdialysis to measure CRH release corticosterone pretreatment potentiates the expression of $\mathrm{CRH}$ in both the amygdala and frontal cortex (Merali et al., 2008). 
Both consumption of and withdrawal from diverse psychotropic drugs elevates glucocorticoids and CRH (Koob and LeMoal, 2005); glucocorticoids like dopamine are essential for organization of action. In fact, that is one of the ways in which the steroid, by regulating the neurotransmitter, influences behavior. In this case, it is an all-too-real occurrence, namely the vulnerability to self-medication with drugs that are harmful. Feedforward systems include adrenal steroids and their regulation of $\mathrm{CRH}$ and adrenergic action in the attention and effort required that underlies the organization of action under adaptive and pathological conditions (Koob and LeMoal, 2005).

Allostatic states reflect the escalation of dependence and the decrease in reward (Koob and LeMoal, 2005; Sterling, 2004). Glucocorticoids regulate a number of neuropeptides and neurotransmitters knotted to the organization of action. In other words, glucocorticoids regulate dopamine, knotted to some aspect of reward or instrumental response (Di Chiara, 1999; Ikemoto and Panksepp, 1999; Koob and LeMoal, 2001, 2005).

\section{EPIGENETIC EVENTS AND SOCIAL CONTACT}

Interestingly, oxytocin and $\mathrm{CRH}$ are also altered by maternal care across generations of offspring. Cross-fostering studies in rodents have shown that variation in maternal care is transmitted in both genomic and non-genomic mechanisms; individual differences in maternal behavior are transmitted from one generation to another (Francis et al., 1999; Meaney, 2001; Champagne, 2003).

One example is the link between maternal licking and grooming (high or low) which is consistently transmitted to female offspring; moreover, decreased social comforting contact has long-term implications for most mammals studied (e.g., Levine, 1975; Meaney et al., 1996; Liu et al., 1997). There is wide variation in this phenomenon that has long-term implications on cephalic systems; those rat pups comforted by social contact have greater regulatory capacity as adults on diverse systems in the brain, including neuropeptide and neurotransmitter systems (dopamine, serotonin, $\mathrm{CRH}$ ).

David Crews rightly emphasized a distinction between a molecular and molar level of analysis. The molar level is a critical level of analysis with regard to epigenesis when the consideration is behavioral adaptation and toward an understanding of development (Crews, 2008). Behavioral adaptations are long noted to be fundamental to evolutionary change, and indeed underlie any definition of evolutionary change (Darwin, 1958; James, 1952). One mechanism that may underlie epigenetic gene regulation is methylation and demethylation (e.g., silencing or enhancing the expression of genes; Holliday, 2002); demethylation prevents transcriptional expression, and one result is the silencing of gene expression. (Holliday and Ho, 1998; Keverne and Curley, 2008).

Variations in parental behaviors, for instance, are linked to oxytocin (or prolactin) expression (Dixson and George, 1982; Carter et al., 1999; Francis et al., 1999, 2002; Keverne and Curley, 2008). The high levels of grooming in cross-fostering experiments are knotted to estrogen and oxytocin expression (Meaney, 2001; Cameron et al., 2008), as well as glucocorticoid receptors and diverse neurotransmitter and neuropeptide expression such as CRH, 5HT, dopamine, and DNA methylation (Weaver et al., 2004). Research is showing both epigenetic and genetic contributions to group formation and regulation and ultimately to reproductive success (Meaney, 2001;
Keverne and Curley, 2008). Genes that produce oxytocin expression, for example, an important peptide hormone that plays diverse regulatory roles from milk lactation, to parturition, to social attachment, are particularly significant; the same hormone depending upon where it is expressed in end organ systems, thus, plays a wide variety of roles (Carter et al., 1999).

Importantly, changes in demethylation are linked to the transmission of these social behaviors to the offspring during development in cross-fostering experiments. They are also linked to CRH (Elliot et al., 2010). Indeed manipulations of demethylation impact the transmission of this social behavior and can be reversed later in life (Weaver et al., 2004). The imprinted genes are not permanent; the emphasis on silencing gene expression by imprinting is of course an active area of research (Cameron et al., 2008).

\section{SOCIAL REGULATION AND ALLOSTATIC OVERLOAD}

Many of the prosocial behaviors and the evaluative processes in cephalic systems are anticipatory and not only reactive to events. Information molecules such as $\mathrm{CRH}$ (or oxytocin or vasopressin) underlie diverse forms of anticipatory behaviors. The concept of "allostasis" is in part to take account of anticipatory control (Sterling and Eyer, 1988) amidst diverse forms of adaptation underlying this regulatory adaptation that supports social contact and internal milieu (Schulkin, 2003). Importantly, feedforward and social regulation of neuropeptide expression is an important factor.

Social contact is at the heart of ontogenetic development, a long noted piece of epistemological history differently expressed across diverse cultures. Family and group structure through meaningful contact is essential for our mental health. Supportive social contact is not an absolute prophylactic but a helpful ameliorative in combating disease and breakdown (Steptoe et al., 2002), along with predictive abilities (Miller, 1957, 1959); intermittent unpredictable aversive events are a long known production of pathology (e.g., gastric Weiss, 1970), increasing allostatic load (e.g., Schulkin et al., 1998; Tannenbaum et al., 2002).

Unremitting social distress, high cortisol when cumulative, decreases social competence process (e.g., brain morphology and decreases in memory function (Sapolsky, 1992, 1995), and increases allostatic load (McEwen and Stellar, 1993; Johnston-Brooks et al., 1998; McEwen, 1998; Seeman et al., 2001). Allostatic load is one predictive factor in aging (Karlamangla et al., 2002; Hellhammer et al., 2004); age, health, and economic disparities are all functionally related to allostatic overload (Crimmins et al., 2003; von Kanel et al., 2003; Carlson and Chamberlain, 2005; Szanton et al., 2005).

The price of an enlarged cortical and limbic systems with greater motivational lures, and one of the original insights of Sterling and Eyer (1988, see also Sterling, 2004), is the chronic over-activation of behavioral and physiological systems; lights are on too long, too little sleep, too little enjoyment, too much seduction by noise, too little rest and restoration and meditation.

Adequate forms of social attachments in our species and in other primates (Harlow and Soumi, 1971; Levine, 1975; Ellison and Gray, 2009), are crucial to normal development, and many forms of social isolation lead to aberrant development. From the mundane to the extraordinary, hormones such as cortisol are knotted to the parental or other forms of attachment (Fleming et al., 1997; Ahnert et al., 2004). 
Social affiliation is one long noted adaptation (Singer and Ryff, 1999; Taylor et al., 2000). A behavioral disposition toward more "dove-like" behavior rather than "hawk-like" behavior, to more collaborative and positive social cooperative interactions, may have real consequences (e.g., conduct disorder for the hawk and anxiety vulnerability for the dove on allostatic overload and vulnerability to physiological pathology; Korte et al., 2004). But they should not be oversold and over-exaggerated.

It is not helped by diverse chronic social, economic health, danger, and worries that permeate our social milieu (Sterling and Eyer, 1988; Schnorpfeil et al., 2003; Carlson and Chamberlain, 2005), such as economic disparities (Steptoe et al., 2002, 2004); elevated cortisol is linked to social economic equality and allostatic overload and wear and tear on regulatory systems (Lupien et al., 2000, 2007). But elevated cortisol should also be elevated in highly socially competitive achievers. The issue is whether the social milieu allows for appropriate secretion and non-secretion of this and other information molecules essential for adapting to diverse social contexts.

Allostatic overload, for instance, by exaggerated levels of cortisol, sets the stage for a wellspring of devolution of function and exaggerated breakdown of bodily tissue (Sapolsky, 1992; McEwen, 1998; Schulkin, 2003; Koob and LeMoal, 2005; Lupien et al., 2007); one ameliorative factor is social meaning, or contact (Jaspers, 1997; Huppert et al., 2005).

\section{CONCLUSION}

The concept of allostasis in its original meaning was tied to diverse and expanding social demands. In fact, a close look at regulation almost always reveals something more than simple reflexes to deviations from set point parameters. In the social domain, and with a consideration of evolution, enhanced use of behavior and social skills emerged to regulate viability.

Social isolation and loneliness is devolution of the ameliorative social factor (Singer and Ryff, 1999; Weinstein et al., 2003; Steptoe et al., 2004; Cacioppo et al., 2006). In other conditions that might be favorable to neuroendocrine systems, social isolation exacerbates vulnerabilities across diverse species (Cacioppo et al., 2006; Grippo et al., 2007).

The endless allure of modern seductive incentives, both social and non-social, are a chronic setting of the stage for allostatic breakdown of function; neuropeptides that serve adaptive roles, such as $\mathrm{CRH}$ in attention to events, now serve as an allure toward devolution of function.

Allostatic regulation is now tied to the physiology of change and adaptation, a core feature of our evolution and the structural formation of our cephalic expansion. The degree of corticalization of function corresponds to the expanded connectivity of cortex

\section{REFERENCES}

Abbott,D.H., Keverne,E.B., Bercovitch, F.B., Shively, C. A., Mendoza, S. P., Saltzman, W., Snowdon, C. T., Ziegler, T. E., Banjevic, M., Garland, T., and Sapolsky, R. M. (2003). Are subordinates always stressed? A comparative analysis of rank differences in cortisol levels among primates. Horm. Behav. 43, 67-82.

Adkins-Regan, E. (2005). Hormones and animal social behavior. Princeton, NJ: Princeton University Press.
Ahnert, L., Gunnar, M. R., Lamb, M. E., and Barthel, M. (2004). Transition to childcare: associations with infantmother attachment, infant negative emotion, and cortisol elevations. Child Dev. 75, 639-650.

Arnold, A. P., and Breedloev, S. M. (1985). Organizational and activational effects of sex steroids on brain and behavior: a reanalysis. Horm. Behav. 19, 469-498.

Barger, N., Stefanacci, L., and Semendeferi, K. (2007). A comparative volumetric

and diverse brain regions that underlie behavior (Sterling, 2004). A greater form of regulation is adapting to changing circumstance, one mechanism of which is allostatic regulation. The expansion of anticipatory regulation of the social and the internal milieu is a reflection of allostasis. The move from reflexive to more anticipatory functions knotted to a cognitive repertoire is a core feature of allostatic regulation of the internal milieu (Sterling and Eyer, 1988; Schulkin, 2003).

Allostatic regulation is the lifeblood of cephalic innervations of adaptive physiological and behavioral responses (McEwen and Wingfield, 2003, Schulkin, 2003; Sterling, 2004). Many of the prosocial behaviors and the evaluative processes in cephalic systems are anticipatory, not merely reactive, to events.

Allostatic overload is a chronic social fact; the origins of the concept of allostasis emphasize the social milieu (Sterling and Eyer, 1988; Schulkin, 2003), and social status is important to vulnerabilities (Kubzansky et al., 1999; Singer and Ryff, 1999; Van Cauter and Spiegel, 1999; Goymann and Wingfield, 2004; Weinstein, 2003).

An essential part of our well-being is in the link to others; human flourishing is bound to others (Jaspers, 1997; Ryff et al., 2004). It is within the social milieu in which approach and avoidance behavioral responses for participation with others occurs; our evolutionary machinery sets the stage for this modern and ancient participation with others and for our sense of well-being (e.g., Fromm, 1947; Ostwald, 1962; Keverne, 2004a,b). This is the sense in which to couch the concept of social allostasis and modern human life.

Human well-being is in part a physiological concept, but since we are social animals, it almost always involves our relationship to others, the diverse and essential meaningful experiences we derive from social contact (Jaspers, 1997). Friendship, compassion, and connectedness to one another are essential for our mental health (Ostwald, 1962; Cacioppo et al., 2006), and our sense of well-being (Jaspers, 1997). The value of meaningful social contact is something featured in other primates (Palombit et al., 1997) and essential for normal development and long-term viability.

As Jaspers (1997), a noted existential psychiatrist stated at the beginning of the twentieth century, “... we are always being led by ideas to a complex unity of meaningful connections ..." (p. 760). The search for meaning underlies human existence, and a great deal of it is social in nature. As the poet Robert Burns put it, "The deities that I adore are social peace and plenty" (from Song). An evolved social framework is an essential feature of the central nervous system; and what evolved are elaborate behavioral ways in which to sustain and maintain the physiological/endocrine systems that underlie the behavioral adaptations.

analysis of the amygdaloid complex and basolateral division in the human and ape brain. Am. J. Phys. Anthropol. 134, 392-403.

Barton, R. A. (2006). Primate brain evolution: integrating comparative neurophysiological and ethological data. Evol. Anthropol. 15, 224-236.

Barton, R. A., Aggleton, J. P., and Greyner, R. (2003). Evolutionary coherence of the mammalian amygdala. Proc. R. Soc. Lond. B Biol. Sci. 270, 539-543.
Bauman, D. E. (2000). "Regulation of nutrient partitioning during lactation: homeostasis and homeorhesis revisited," in Ruminant Physiology, ed. P. J. Cronje (New York: CAB Publishing), 311-328. Bernard, C. (1859). Lecons surles Proprietes Physiologiques et les Alterations Pathologiques de l'Organisme. Paris: Balliers.

Berridge, K. C. (2004). Motivation concepts in behavioral neuroscience. Physiol. Behav. 81, 179-209. 
Buttemer, W. A., Astheimer, L. B., and Wingfield, J. C. (1991). The effect of corticosterone on standard metabolic rates of small passerine birds. J. Comp. Physiol. 161, 427-431.

Cacioppo, J.T., and Bernston, G. G. (2007). "The brain, homeostasis and health: balancing demands of the internal and external milieu," in Oxford Handbook of Health Psychology, eds H. S. Fiedman and R. Cohen-Silver (Oxford: Oxford University Press), 73-91.

Cacioppo, J. T., Hawkley, L., Ernst, J. M., Burleson, M., Berntson, G. G., Nouriani, B., and Spiegel, D. (2006). Loneliness within a nomological net: an evolutionary perspective. J. Res. Pers. 40, 1054-1085.

Cannon, W. B. (1929). Bodily Changes in Pain, Hunger, Fear and Rage. New York: Appleton and Co.

Cameron, N.M.,Shahrokh, D., Del Corpo, A., Dhir, S. K., Szyf, M., Champagne, F. A., and Meaney, M. J. (2008). Epigenetic programming of phenotypic variations in reproductive strategies in the rat through maternal care. J. Neuroendocrinol. 20, 795-801.

Cannon, W. B. (1963). The Wisdom of the Body. New York: W. W. Norton.

Carlson, E. D., and Chamberlain, R. M. (2005). Allostatic load and health disparities: a theoretical orientation. Res. Nurs. Health 28, 306-315.

Carpenter, R. H. S. (2004). Homeostasis: a plea for a unified approach. $A d v$. Physiol. Educ. 28, 180-187.

Carter, C. S., Lederhendler, I. L., and Kirkpatrick, B. (1999). The Integrative Neurobiology of Affiliation. Cambridge: MIT Press.

Cavigelli, S. A., Dubovick, T., Levash, W., Jolly, A., and Pitts, A. (2003). Female dominance status and fecal corticoids in a cooperative breeder with low reproductive skew: ring-tailed lemurs. Horm. Behav. 43, 166-179.

Champagne, F. A. (2003). Variations in maternal care in the rat as a mediating influence for the effects of environment on development. Physiol. Behav. 79, 359-371.

Cheney, D. L., and Seyfarth, R. M. (1990). How Monkeys See the World. Chicago: University of Chicago Press.

Cheney, D. L., and Seyfarth, R. M. (2007). Baboon Metaphysics. Chicago, IL: University of Chicago Press.

Choleris, E., Devidze, N., Kavaliers, M., and Pfaff, D. W. (2008). "Steroidal/ neuropeptides interactions in hypothalamus and amygdala related to social anxiety," in Progress in Brain Research, Vol. 170, eds I. D. Neumann and R. Landgraf, (Oxford, UK), 291-303.

Chrousos, G. P. (1996). The hypothalamic-pituitary-adrenal axis and immunomediated inflammation. N. Eng. J. Med. 332, 1351-1362.
Chrousos, G. P., and Gold, P. W. (1992). The concepts of stress and stress system disorders: overview of physical and behavioral homeostasis. J. Am. Med. Assoc. 267, 1244-1252.

Cook, C. J. (2002). Glucocorticoid feedback increases the sensitivity of the limbic system to stress. Physiol. Behav. 75, 455-464.

Coplan, J.D., Andrews, M.W., Rosenblum, L. A., Owens, M. J., Friedman, S., Gorman, J. M., and Nemeroff, C. B. (1996). Persistent elevations of cerebrospinal fluid concentrations of corticotropin-releasing factor in adult nonhuman primates exposed to early-life stressors: implications for the pathophysiology of mood and anxiety disorders. Proc. Natl. Acad. Sci. U.S.A. 93, 1619-1623.

Creel, S. (2001). Social dominance and stress hormones. Trends Ecol. Evol. 16, 491-497.

Crews, D. (2008). Epigenetics and its implications for behavioral neuroendocrinology. Front. Neuroendocrinol. 29, 344-357.

Crimmins, E. M., Johnston, M., Hayward, M., and Seeman, T. (2003). Age differences in allostatic load: an index of physiological dysregulation. Exp. Gerontol. 38, 731-734.

Dallman, M. F. (2003). Stress by any other name? Horm. Behav. 43, 18-20.

Dallman, M. F., Pecoraro, N., Akana, S. F., La Fleur, S. E., Gomez, F., Houshyar, H., Bell, M. E., Bhatnagar, S., Laugero, K. D., and Manalo, S. (2003). Chronic stress and obesity: a new view of "comfort food". Proc. Natl. Acad. Sci. U.S.A. 100, 11696-11701.

Dallman, M. F., Akana, S. F., Cascio, C. S., Darlington, D. N., Jacobson, L., and Levin, N. (1987). Regulation of ACTH secretion: variations on a theme of $\mathrm{B}$. Recent Prog. Horm. Res. 43, 113-173.

Dallman, M. F., Akana, S. F., Levin, N., Walker, C. D., Bradbury, M. J., Suemaru, S., and Scribner, K. S. (1994). Corticosteroids and the control of function in the hypothalamopituitary-adrenal (HPA) axis. Ann. N. Y. Acad. Sci. 747, 22-31; discussion 31-32, 64-67.

Darwin, C. (1874). The Descent of Man and Selection in Relation to Sex. Chicago: Rand, McNally and Co.

Darwin, C. (1958). The Origin of Species. New York: Mentor Book.

Darwin, C. (1998). The Expression of the Emotions in Man and Animals. Oxford: Oxford University Press.

Day, T. A. (2005). Defining stress as a prelude to mapping its neurocircuitry: no help from allostasis. Prog. Neuropsychopharmacol. Biol. Psychiatry 29, 1195-1200.

Di Chiara, G. (1999). Drug addiction as dopamine-dependent associa- tive learning. Eur. J. Pharmacol. 375, 13-30.

Dixson, A. F., and George, L. (1982). Prolactin and parental behaviour in a male New World primate. Nature 299, 551-553.

Donley, M. P., Schulkin, J., and Rosen, J. B. (2005). Glucocorticoid receptor antagonism in the basolateral amygdala and ventral hippocampus interferes with long-term memory of contextual fear. Behav. Brain Res. 164, 197-205.

Dunbar, R. I. M. (1998). The social brain hypothesis. Evol. Anthropol. 6, 178-190.

Dunbar, R. I. M., and Shultz, S. (2007). Evolution in the social brain. Science 317, 1344-1347.

Eberhart, J. A., Keverne, E. B., and Meller, R. E. (1980). Social influences on plasma testosterone levels in male talapoin monkeys. Horm. Behav. 14, 247-266.

Elliot, E., Ezra-Nevo, G., Regev, L., Neufeld-Cohen, A., and Chen, A. (2010). Resilience to social stress coincides with functional DNA methylation of the Crf gene in adult mice. Nat. Neurosci. 13, 1351-1353.

Ellison, T. T., and Gray, P. B. (2009). Endocrinology of Social Relationships. Cambridge: Harvard University Press.

Engh, A. L., Beehner, J. C., Bergman, T. J., Whitten, P. L., Hoffmeier, R. R., Seyfarth, R. M., and Cheney, D. L. (2006a). Female hierarchy instability, male immigration and infanticide increase glucocorticoid levels in female chacma baboons. Anim. Behav. 71, 1227-1337.

Engh, A. L., Beehner, J. C., Bergman, T. J., Whitten, P. L., Hoffmeier, R. R., Seyfarth, R. M., and Cheney, D. L. (2006b). Behavioral and hormonal responses to predation in female chacma baboons (Papio hamadryas ursinus). Proc. Biol. Sci. 273, 707-712.

Erickson, K., Gabry, K. E., Lindell, S., Champoux, M., Schulkin, J., Gold, P., Suomi, S. J., and Higley, J. D. (2005). Social withdrawal behaviors in nonhuman primates and changes in neuroendocrine and monoamine concentrations during a separation paradigm. Dev. Psychobiol. 46, 331-339.

Falk, D. (1983). Cereberal cortices of east African early hominids. Science 221, 1072-1074.

Fink, G. (1997). "Mechanisms of negative and positive feedback of steroids in the HPA system," in Principles of Medical Biology, Vol. 10, eds E. E. Bittar and N. Bittar (New York: JAI Press) 29-30.

Fitzsimons, J. T. (1999). Angiotensin, thirst and sodium appetite. Physiol. Rev. 76, 583-686.

Fleming, A. S., Ruble, D., Krieger, H., and Wong, P. Y. (1997). Hormonal and experiential correlates of maternal responsiveness during pregnancy and the puerperium in human mothers. Horm. Behav. 31, 145-158.

Fleming, A. S., Steiner, M., and Corter, C. (1997). Hormones, hedonics and maternal responsiveness in human mothers. Horm. Behav. 32, 85-98.

Fluharty, S. J., and Epstein, A. N. (1983). Sodium appetite elicited by intracerebroventricular infusion of angiotensin II in the rat: II. Synergistic interaction with systemic mineralocorticoids. Behav. Neurosci. 97, 746-758.

Foley, R. (1996). An evolutionary and chronological framework for human social behaviour. Proc. Br. Acad. 88, 95-117.

Francis, D. D., Diorio, J., Liu, D., and Meaney, M. J. (1999). Nongenomic transmission across generations of maternal behavior and stress responses in the rat. Science 286, 1155-1158.

Francis, D. D., Young, L. J., Meaney, M. J., and Insel, T. R. (2002). Naturally occurring differences in maternal care are associated with the expression of oxytocin and vasopressin (V1a) receptors: gender differences. J. Neuroendocrinol. 14, 349-353.

Freud, S. (1959). Inhibitions, Symptoms and Anxiety. (A. Strachey, Trans.). Revised and newly edited by James Strachey. New York: W.W. Norton.

Fromm, E. (1947). Man for himself. New York: Rinehart \& Company.

Ganzel, B. L., Morris, P. A., and Wethington, E. (2010). Allostasis and the human brain: integrating models of stress from the social and life sciences. Psychol. Rev. 1, 134-174.

Gluckman, P. D., Hanson, M. A., and Spencer, H. G. (2005). Predictive adaptive responses and human evolution. Trends Ecol. Evol. 20, 527-533.

Goldstein, D. S. (1995). Stress, catecholamines, and cardiovascular disease. New York: Oxford University Press.

Goodson,J.L. (2005). The vertebrate social behavioral network: evolutionary themes and variations. Horm. Behav. $48,11-22$.

Goy, R. W., and McEwen, B. S. (1980). Sexual differentiation of the brain. Cambridge, MA: MIT Press.

Goymann, W., and Wingfield, J.C. (2004). Allostatic load, social status and stress hormones: the costs of social status matter. Anim. Behav. 67, 591-602.

Grippo, A. J., Gerena, D., Huang, J., Kumar, N.,Shah, M., Ughreja, R., and Carter, C. S. (2007). Social isolation induces behavioral and neuroendocrine disturbances relevant todepression in female and male prairie voles. Psychoneuroendocrinology $32,966-980$.

Gunnar, M. R. (1998). Quality of early care and buffering or neuroendocrine stress reactions: potential effects on the 
developing human brain. Prev. Med. 27, 208-211.

Gunnar, M. R., and Davis, E. P. (2005). "Stress and emotion in early childhood," in Comprehensive handbook of psychology, Vol. 6, Developmental psychology, eds R. M. Lerner, M. A. Easterbrooks, and J. Mistry (New York: Wiley), 113-134.

Gunnar, M. R., Mangelsdorf, S., Larson, M., and Hertsgaard, L. (1989). Attachment, temperament, and adrenocortical activity in infancy: a study of psychoendocrine regulation. Dev. Psychol. 25, 355-363.

Habib, K. E., Weld, K. P., Rice, K. C., Pushkas, J., Champoux, M., Listwak, S., Webster, E. L., Atkinson, A. J., Shulkin, J., Contoreggi, C., Chrousos, G. P., McCann, S. M., Suomi, S. J., Higley, J. D., and Gold, P. W. (2000). Oral administration of a corticotropin-releasing hormone receptor antagonist significantly attenuates behavioral, neuroendocrine, and autonomic responses to stress in primates. Proc. Natl. Acad. Sci. U.S.A. 97, 6079-6084.

Harlow, J. F., and Soumi, S. J. (1971). Social recovery by isolation reared monkeys. Proc. Natl. Acad. Sci. U.S.A. 68, 1534-1538.

Hellhammer, J., Schlotz, W., Stone, A. A., Pirke, K. M., and Hellhammer, D. (2004). Allostatic load, perceived stress, and health: a prospective study in two age groups. Ann. N. Y. Acad. Sci. 1032, 8-13.

Herbert, J. (1993). Peptides in the limbic system: neurochemical codes for co-ordinated adaptive responses to behavioral and physiological demand. Prog. Neurobiol. 41, 723-791.

Herbert, J., and Schulkin, J. (2002). "Neurochemical coding of adaptive responses in the limbic system," in Hormones, Brain and Behavior, ed. D. Pfaff (New York: Elsevier Press), 659-690.

Holliday, R. (2002). Epigenetics comes of age in the twenty-first century. J. Genet. 81, 1-4.

Holliday, R., and Ho, T. (1998). Evidence for gene silencing by endogenous DNA methylation. Proc. Natl. Acad. Sci.U.S.A. 95, 8727-8732.

Huppert, F. A., Baylis, N., and Keverne, B. (2005). The Science of Well-Being. Oxford: Oxford University Press.

Ikemoto, S., and Panksepp, J. (1999). The role of nucleus accumbens dopamine in motivated behavior: a unifying interpretation with special reference to reward-seeking. Brain Res. Rev. 31, 6-41.

Imaki, T., Nahan, J. L., Rivier, C., and Vale, W. (1991). Differential regulation of corticotropin releasing hormone mRNA in rat brain regions by gluco- corticoids and stress. J. Neurosci. 11, 585-598.

Insel, T. R., and Fernald, R. D. (2004). How the brain processes social information. Annu. Rev. Neurosci. 27, 697-722.

James, W. (1952). The Principles of Psychology. New York: Dover Press.

Jaspers, K. (1997). General Psychopathology, Vol. I and II. (J. Hoenig and M. W. Hamilton, Trans.) Baltimore: The Johns Hopkins University Press.

Johnston-Brooks, C. H., Lewis, M. A., Evans, G. W., and Whalen, C. K. (1998). Chronic stress and illness in children: the role of allostatic load. Psychosom. Med. 60, 597-603.

Kagan, J. (1984). The Nature of the Child. New York: Basic Books.

Kalin, N. H. (1985). Biological effects of corticotropin releasing hormone administered to rhesus monkeys. Fed. Proc. 44, 249-253.

Kalin, N. H., Larson, C., Shelton, S.E., and Davidson, R. J. (1998). Asymmetric frontal brain activity, cortisol, and behavior associated with fearful temperament in rhesus monkeys. Behav. Neurosci. 112, 286-292.

Kalin, N. H., Shelton, S. E., and Barksdale, C. M. (1989). Behavioral and physiologic effects of $\mathrm{CRH}$ administered to infant primates undergoing maternal separation. Neuropsychopharmacology 2, 97-104.

Kalin, N. H., Shelton, S. E., and Davidson, R. J. (2000). Cerebrospinal fluid corticotropin-releasing hormone levels are elevated in monkeys with patterns of brain activity associated with fearful temperament. Biol. Psychiatry 47, 579-585.

Kalya, S.P. (1993). Mandatory neuropeptide-steroid signaling for the preovulatory luteinizing hormone-releasing hormone discharge. Endocr. Rev. 14, 507-538.

Karlamangla,A. S., Singer, B. H., McEwen, B. S., Rowe, J. W., and Seeman, T. E. (2002). Allostatic load as a predictor of functional decline. MacArthur studies of successful aging. J. Clin. Epidemiol. 55, 696-710.

Keverne, E. B. (2004a). Brain evolution, chemosensory processing, and behavior. Nutr. Rev. 62, S218-S223; discussion S224-S241.

Keverne, E. B. (2004b). Understanding well-being in the evolutionary context of brain development. Philos. Trans. R. Soc. Lond. B Biol. Sci. 359, 1349-1358.

Keverne, E. B., and Curley, J. P. (2004). Vasopressin, oxytocin and social behavior. Curr. Opin. Neurobiol. 14, 777-783.

Keverne, E. B., and Curley, J. P. (2008). Epigenetics, brain evolution and behavior. Front. Neuroendocrinol. 29, 398-412.
Kolber, B. J., Roberts, M. S., Howell, M. P., Wozniak, D. F., Sands, M. S., and Muglia, L. J. (2008). Central amygdala glucocorticoid receptor action promotes fear-associated CRH activation and conditioning. Proc. Natl. Acad. Sci. U.S.A. 105, 12004-12009.

Koob, G. F., and LeMoal, M. (2001). Drug addiction, dysregulation of reward, and allostasis. Neuropsychopharmacology 24, 94-129.

Koob, G. F., and LeMoal, M. (2005). Neurobiology of Addiction. New York: Elsevier.

Korte, S. M., Koolhaas, J. M., Wingfield, J. C., and McEwen, B. S. (2004). The Darwinian concept of stress: benefits of allostasis and costs of allostatic load and the trade-offs in health and disease. Neurosci. Biobehav. Rev. 29, 3-38.

Kubzansky, L.D., Kawachi, I., and Sparrow, D. (1999). Socioeconomic status, hostility, and risk factor clustering in the Normative Aging Study: any help from the concept of allostatic load? Ann. Behav. Med. 21, 330-338.

Kukolja, J., Schlapfer, T. E., Keysers, C., Klingmüller, D., Maier, W., Fink, G. R., and Hurlemann, R. (2008). Modeling a negative response in the human amygdala by noradrenergic-glucocorticoid interactions. J. Neurosci. 28, 12868-12876.

Landys, M. M., Ramenofsky, M., and Wingfield, J. C. (2006). Actions of glucocorticoids at a seasonal baseline as compared to stress-related levels in the regulation of periodic life processes. Gen. Comp. Endocrinol. 148, 132-149.

Levine, S. (1975). "Psychosocial factors in growth and development," in Society, Stress, and Disease, ed. L. Levi (London: Oxford University Press), 43-50.

Liu, D., Diorio, J., Tannenbaum, B., Caldji, C., Francis, D., Freedman, A., Sharma, S., Pearson, D., Plotsky, P. M., and Meaney, M. J. (1997). Maternal care, hippocampal glucocorticoid receptors, and hypothalamic-pituitaryadrenal responses to stress. Science 277, 1659-1662.

Lorenz, K. (1965). Evolution and Modification of Behavior. Chicago: University of Chicago Press.

Lorenz, K. (1981). The Foundations of Ethology. New York: Springer.

Lupien, S. J., King, S., Meaney, M. J., and McEwen, B. S. (2000). Child's stress hormone levels correlate with mother's socioeconomic status and depressive state. Biol. Psychiatry 48, 976-980.

Lupien, S. J., Maheu, F., Tu, M., Fiocco, A., and Schramek, T. E. (2007). The effects of stress and stress hormones on human cognition: implications for the field of brain and cognition. Brain Cogn. 65, 209-237.
Makino, S., Gold, P. W., and Schulkin, J. (1994a). Corticosterone effects on corticotropin-releasing hormone mRNA in the central nucleus of the amygdala and the parvocellular region of the paraventricular nucleus of the hypothalamus. Brain Res. 640, 105-112.

Makino, S., Gold, P. W., and Schulkin, J. (1994b). Effects of corticosterone on CRH mRNA and content in the bed nucleus of the amygdala and the paraventricular nucleus of the hypothalamus. Brain Res. 657, 141-149.

Makino, S., Schulkin, J., Smith, M. A., Pacak, K., Palkorits, M., and Gold, P.W. (1995). Regulation of corticotropinreleasing hormone receptor messenger ribonucleic acid in the rat brain and pituitary by glucocorticoids and stress. Endocrinology 136, 4517-4525.

McCarthy, M. M. (2008). Estradiol and the developing brain. Physiol. Rev. 88, 91-134.

McEwen, B. S. (1995). Steroid actions on neuronal signalling. Ernst Schering Res. Found. Lect. Ser. 27, 1-45.

McEwen, B. S. (1998). Protective and damaging effects of stress mediators. N. Engl. J. Med. 338, 171-179.

McEwen, B. S. (2007). Physiology and neurobiology of stress and adaptation: central role of the brain. Physiol. Rev. 87, 873-904.

McEwen, B. S., and Stellar, E. (1993). Stress and the individual: mechanisms leading to disease. Arch. Int. Med. 153, 2093-3101.

McEwen, B. S., and Wingfield, J.C. (2003). The concept of allostasis in biology and medicine. Horm. Behav. 41, 2-15.

McEwen, B.S., and Wingfield, J.C. (2010). What's in a name? Integrating homeostasis, allostasis and stress. Horm. Behav. 57, 105-111.

McGaugh, J. L. (2000). Memory - A century of consolidation. Science 287, 248-251.

McGaugh, J.L. (2003). Memory and emotion. New York: Columbia University Press.

Meaney, M. J. (2001). Maternal care, gene expression, and the transmission of individual differences in stress reactivity across generations. Annu. Rev. Neurosci. 24, 1161-1192.

Meaney, M. J., Diorio, J., Francis, D., Widdowson, J., LaPlante, P., Caldji, C., Sharma, S., Seckly, J. R., and Plotsky, P. M. (1996). Early environmental regulation of forebrain glucocorticoid receptor gene expression: implications for adrenocortical responses to stress. Dev. Neurosci. 18, 49-72.

Merali, Z., Anisman, H., James, J. S., Kent, P., and Schulkin, J. (2008). Effects of corticosterone on CRH and gastrinreleasing peptide release in response to an aversive stimulus in two regions 
of the forebrain. Eur. J. Neurosci. 28, 165-172.

Merali, Z., McIntosch, J., and Anisman, H. (2004). Anticipatory cues differentially provoke in vivo peptidergic and monomaninertic release at the medial prefrontal cortex. Neuropharmacology 29, 1417-1418.

Merali,Z., McIntosh, J., Kent, P., Michaud, D., and Anisman, H. (1998). Aversive and appetitive events evoke the release of corticotropin-releasing hormone and bombesin-like peptides at the central nucleus of the amygdala. $J$. Neurosci. 18, 4758-4766.

Miller, N.E. (1957). Experiments of motivation. Studies combining psychological, physiological, and pharmacological techniques. Science 126, 1271-1278.

Miller, N. E. (1959). "Liberalization of basicc S-R concepts: extensions to conflict behaviour, motivation and social learning," in Psychology: A Study of a Science, ed. S. Koch, Vol. 2 (New York: McGraw-Hill), 196-292.

Moore-Ede, M. C. (1986). Physiology of the circadian timing system: predictive versus reactive homeostasis. Am. J. Physiol. 250, R737-R752.

Moore-Ede, M. C., Sulzman, F. M., and Fuller, C. A. (1992). The clocks that time us. Cambridge, UK: Harvard University Press.

Nachmias, M., Gunnar, M., Mangelsdorf, S., Hornik Parritz, R., and Buss, K. (1996). Behavioral inhibition and stress reactivity: the moderating role of attachment security. Child Dev. 67, 508-522.

Ostwald, M. (1962). Aristotle's Nicomachean ethics. New York: Macmillan.

Mrosovsky, N. (1990). Rheostasis, The physiology of Change. New York: Oxford University Press.

Palombit, R. A., Seyfarth, R. M., and Cheney,D.L.(1997). The adaptive value of "friendships" to female baboons: experimental and observational evidence. Anim. Behav. 54, 599-614.

Peciña, S., Schulkin, J., and Berridge, K. C. (2006). Nucleus accumbens corticotropin-releasing factor increases cue-triggered motivation for sucrose reward: paradoxical positive incentive effects in stress? BMC Biol. 4, 8. doi: 10.1186/1741-7007-4-8

Pfaff, D. W. (1980). Estrogens and brain function. New York: Springer-Verlag.

Pfaff, D. W. (1999). Drive. Cambridge: MIT Press.

Power, M. L. (2004). "Viability as opposed to stability: an evolutionary perspective on physiological regulation," in Allostasis, Homeostasis and the Costs of Adaptation, ed. J. Schulkin (Cambridge: Cambridge University Press), 343-364.
Power, M. L., and Schulkin, J. (2009). Evolution of Obesity. Baltimore: Johns Hopkins University Press.

Richter, C. P. (1943). Total self-regulatory functions in animals and human beings. Harvey Lect. 38, 367-371.

Ricklefs, R. E., and Wikelski, M. (2002). The physiology/life history nexus. Trends Ecol. Evol. 17, 462-466.

Robinson, T.E., and Berridge, K.C. (1993). The neural basis of drug craving: an incentive-sensitization theory of addiction. Brain Res. Rev. 18, 247-291.

Robson, S., and Wood, B. (2008). Hominin life history: reconstruction and evolution. J. Anat. 212, 394-425.

Romero, L. M., Dickens, M. J., and Cyr, N. E. (2009). The reactive scope model-a new model integrating homeostasis, allostasis, and stress. Horm. Behav. 55, 375-389.

Roozendaal, B. (2000). Glucocorticoids and the regulation of memory consolidation. Psychoneuroendocrinology 25, 213-238.

Roozendaal, B., Brunson, K. L., Holloway, B. L., McGaugh, J. L., and Baram, T. Z. (2002). Involvement of stress-released corticotropin-releasing hormone in the basolateral amygdala in regulating memory consolidation. Proc. Natl. Acad. Sci. U.S.A. 99, 13908-13913.

Roozendaal, B., Carmi, O., and McGaugh, J. L. (1996). Adrenocortical suppression blocks the memory-enhancing effects of amphetamine and epinephrine. Proc. Natl. Acad. Sci. U.S.A.93, 1429-1433.

Roozendaal, B., de Quervain, D. J. F., Ferry, B., Setlow, B., and McGaugh, J. L. (2001). Basolateral amygdala-nucleus accumbens interactions in mediating glucocorticoid enhancement of memory consolidation. J. Neurosci. 21, 2518-2525.

Ruscio, M. G., Sweeny, T., Hazelton, J., Suppatkul, P., and Carter, C. S. (2007). Social environment regulates corticotropin releasing factor, corticosterone and vasopressin in juvenile prairie voles. Horm. Behav. 51, 54-61.

Ryff, C. D., Singer, B. H., and Dienberg Love G. (2004). Positive health: connecting well-being with biology. Philos. R. Soc. Lond. B Biol. Sci. 359, 1386-1394.

Saltzman, W., Schultz-Darken, N. J., Scheffler, G., Wegner, F. H., and Abbott, D. H. (1994). Social and cooperative influences on plasma cortisol in female marmoset monkeys. Physiol. Behav. 56, 801-819.

Saltzman, W., Schultz-Darken, N. J., Wegner, F. H., Wittwer, D. J., and Abbott, D. H. (1998). Suppression of cortisol levels in subordinate female marmosets: reproductive and social contributions. Horm. Behav. 33, 58-74.

Sapolsky, R. M. (1990). Adrenocortical function, social rank, and personality among wild baboons. Biol. Psychiatry $28,862-878$.

Sapolsky, R. M. (1992). Stress: The Aging Brain and the Mechanisms of Neuron Death. Cambridge: MIT Press.

Sapolsky, R. M. (1995). Social subordinance as a marker of hypercortisolism. Some unexpected subtleties. Ann. N. Y. Acad. Sci. 771, 626-639.

Sapolsky, R. J., Romero, M., and Munck, A. U. (2000). How do glucocorticoids influence stress responses? Integrating permissive, suppressive, stimulatory, and preparative actions. Endocr. Rev. $21,55-89$.

Schnorpfeil, P., Noll, A., Schulze, R., Ehlert, U., Frey, K., and Fischer, J. W. (2003). Allostatic load and work conditions. Soc. Sci. Med. 57, 647-656.

Schulkin, J. (1999). The Neuroendocrine Regulation of Behavior. Cambridge: Cambridge University Press.

Schulkin,J.(2003). Rethinking Homeostasis. Cambridge: MIT Press.

Schulkin, J., Gold, P.W., and McEwen, B. S. (1998). Induction of corticotropin-releasinghormonegeneexpressionbyglucocorticoids. Psychoneuronedocrinology 23, 219-243.

Seeman, T. E., McEwen, B. S., Rowe, J. W. and Singer, B.H. (2001). Allostatic load as a marker of cumulative biological risk: MacArthur studies of successful aging. Proc. Natl. Acad. Sci.U.S.A. 98, 470-475.

Selye, H. (1956). The Stress of Life. New York: McGraw-Hill.

Shepard, J. D., Barron, K. W., and Myers, D. A. (2000). Corticosterone delivery to the amygdala increases corticotropinreleasing hormonemRNA in the central nucleus of the amygdala and anxietylike behavior. Brain Res. 851, 288-295.

Singer, B., and Ryff, C. D. (1999). Hierarchies of life histories and associated health risks. Ann. N. Y. Acad. Sci. 896, 96-115.

Steptoe, A., Feldman, P. J., Kunz, S., Owen, N., Willemsen, G., and Marmot, M. (2002). Stress responsivity and socioeconomic status: a mechanism for increased cardiovascular disease risk? Eur. Heart J. 23, 1757-1763.

Steptoe, A., Owen, N., Kunz-Ebrecht, S. R., and Brydon, L. (2004). Loneliness and neuroendocrine, cardiovascular, and inflammatory stress responses in middle-aged men and women. Psychoneuroendocrinology 29, 593-611.

Sterling, P. (2004). “Principles of allostasis: optimal design, predictive regulation, psychopathology and rational therapeutics," in Allostasis, Homeostasis and the Costs of Physiological Adaptation, ed.J.Schulkin (Cambridge: Cambridge University Press), 17-64.

Sterling, P., and Eyer, J. (1988). “Allostasis: a new paradigm to explain arousal pathology," in Handbook of Life Stress, Cognition, and Health, eds S. Fisher and J. Reason (New York: John Wiley and Sons), 629-649.

Strand, F. L. (1999). Neuropeptides: Regulators of Physiological Processes. Cambridge, MA: MIT Press.

Stringer, C. B., and Andrews, P. (1988). Genetic and fossil evidence for the origin of modern humans. Science 239, 1263-1268.

Swanson, L. W. (2000). The cerebral hemisphere regulation of motivated behavior. Brain Res. 836, 113-164.

Swanson, L. W., and Simmons, D. M. (1989). Differential steroid hormone and neural influences on peptide mRNA levels in CRH cells of the paraventricular nucleus: a hybridization histochemical study in the rat. J. Comp. Neurol. 285, 413-435.

Szanton, S. L., Gill, J. M., and Allen, J. K. (2005). Allostatic load: a mechanism of socioeconomic health disparities. Biol. Res. Nurs. 7, 7-15.

Tannenbaum, B., Tannenbaum, G. S., Sudom. K., and Anisman, H. (2002). Neurochemical and behavioral alterations elicited by a chronic intermittent stressor regimen: implications for allostatic load. Brain Res. 953, 82-92.

Taylor, S. E., Klein, L. T., Lewis, B. P., Gruenwald, T. L., Gurung, R. A., and Updegraff, J. A. (2000). Biobehavioral responses to stress in females: tend and befriend, not fight or flight. Psychol. Rev. 107, 411-429.

Thompson, B. L., Erickson, K. Schulkin, J., and Rosen, J. B. (2004). Corticosterone facilitates retention of contextual fear conditioning and increases $\mathrm{CRH}$ mRNA expression in the amygdala. Behav. Brain Res. 149, 209-215.

Toates, F. (1986). Motivational Systems. Cambridge: Cambridge University Press.

Tomasello, M. (1999). The Cultural Origins of Human Cognition. Cambridge, MA: Harvard University Press.

Tomasello, M., Kruger, A. C., and Ratner, H.H. (1993). Cultural learning. Behav. Brain Sci. 16, 495-552.

Valentino, R. J., Foote, S. L., and Page, M. E. (1993). The locus coeruleus as a site for integrating corticotropin-releasing factor and noradrenergic mediation of stress responses. Ann. N. Y. Acad. Sci. 697, 173-188.

Van Cauter, E., and Spiegel, K. (1999). Sleep as a mediator of the relationship between socioeconomic status and health: a hypothesis. Ann. N.Y. Acad. Sci. 896, 254-261. 
von Kanel, R., Dimsdale, J. E., Patterson, T. L., and Grant, I. (2003). Acute procoagulant stress response as a dynamic measure of allostatic load in Alzheimer caregivers. Ann. Behav. Med. 26, 42-48.

Watts, A. G., and Sanchez-Watts, G. (1995). Region-specific regulation of neuropeptide mRNAs in rat limbic forebrain neurons by aldosterone and corticosterone. J. Physiol. (Lond.) 484, 721-736.

Weaver, I. C., Cervoni, N., Champagne, F. A., D’Alessio, A. C., Sharma, S., Seckl, J. R., Dymov, S., Szyf, M., and Meaney, M. J. (2004). Epigenetic programming by maternal behavior. Nat. Neurosci. 7, 847-854.

Weinstein, M., Goldman, N., Hedley, A., Yu-Hsuan, L., and Seeman, T. (2003).
Social linkages to biological markers of health among the elderly. J. Biosoc. Sci. 35, 433-453.

Weiss, J. M. (1970). Somatic effects of predictable and unpredictable shock. Psychosom. Med. 32, 397-408.

Wingfield, J. C. (2004). "Allostatic load and life cycles: implication for neuroendocrine control mechanisms," in Allostasis, Homeostasis and the Costs of Physiological Adaptation, ed. J. Schulkin (Cambridge: Cambridge University Press), 302-342.

Wingfield, J. C., Jacobs, J. D., Soma, K., Maney, D. L., Hunt, K., Wisti-Peterson, D., Meddle, S., Ramenofsky, M., and Sullivan, K. (1999). "Testosterone, aggression and communication: ecological bases of endocrine phenomenona," in The design of animal communication, eds M.D. Hauser and M. Konishi (Cambridge: Cambridge University Press), 196-209.

Wingfield, J. C., and Romero, L. M. (2001). "Adrenocortical responses to stress and their modulation in free-living vertebrates," in Coping with the Environment: Neural and Endocrine Mechanisms, ed. B. S. McEwen (Oxford: Oxford University Press), 211-234.

Wood, B. (1992). Origin and evolution of the genus homo. Nature 355, 783-790.

Yao, M., Schulkin, J., and Denver, R. J. (2008). Evolutionary conserved glucocorticoid regulation of $\mathrm{CRH}$. Endorcinology 149, 2352-2360.

Conflict of Interest Statement: The author declares that the research was conducted in the absence of any commercial or financial relationships that could be construed as a potential conflict of interest.

Received: 31 March 2010; paper pending published: 19 December 2010; accepted: 19 December 2010; published online: 31 January 2011.

Citation: Schulkin J (2011) Social allostasis: anticipatory regulation of the internal milieu. Front. Evol. Neurosci. 2:111. doi: 10.3389/fnevo.2010.00111

Copyright (c) 2011 Schulkin. This is an open-access article subject to an exclusive license agreement between the authors and Frontiers Media SA, which permits unrestricted use, distribution, and reproduction in any medium, provided the original authors and source are credited. 